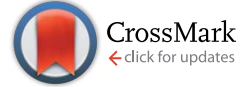

Cite this: J. Mater. Chem. A, 2016, 4, 6433

Received 24th January 2016

Accepted 8th April 2016

DOI: $10.1039 / c 6 t a 00673 f$

www.rsc.org/MaterialsA

\section{Influence of particle size, cycling rate and temperature on the lithiation process of anatase $\mathrm{TiO}_{2} \dagger$}

\begin{abstract}
H. Liu and C. P. Grey*
The nature of a phase transition plays an important role in controlling the kinetics of reaction of an electrode material in a lithium-ion battery. The actual phase transition path can be affected by particle size and cycling rate. In this study, we investigated the phase transition process during the electrochemical Li intercalation of anatase $\mathrm{TiO}_{2}$ as a function of particle size $(25 \mathrm{~nm}$ and $100 \mathrm{~nm})$, cycling rate (1C,2C,5C,10C, 20C) and temperature (room temperature and $80^{\circ} \mathrm{C}$ ) by in situ synchrotron $\mathrm{X}$-ray diffraction. The phase transition was found to be affected by the particle size: the $100 \mathrm{~nm}$ particles react simultaneously via a conventional nucleation and growth, i.e. two-phase, mechanism, while the $25 \mathrm{~nm}$ particles react sequentially via a two-phase mechanism. The Li miscibility gap decreases with increasing cycling rate, yet the phase separation was not suppressed even at a cycle rate of $20 \mathrm{C}$. An increase in temperature from room temperature to $80^{\circ} \mathrm{C}$ significantly improves the electrode's electrochemical performance despite undergoing a two-phase reaction. The failure to observe a continuous structural transition from tetragonal $\mathrm{TiO}_{2}$ to orthorhombic $\mathrm{Li}_{0.5} \mathrm{TiO}_{2}$ even at high rates and elevated temperature was attributed to the high energy barrier of a continuous phase transition path.
\end{abstract}

\section{Introduction}

Most commercial Li ion battery electrodes employ intercalation compounds, such as $\mathrm{LiCoO}_{2}$ and $\mathrm{LiFePO}_{4}$, where $\mathrm{Li}$ insertion and extraction can be reversibly extracted from and inserted into the host structure during battery charge and discharge, respectively. For intercalation compounds, (de)lithiation takes place either by a single-phase reaction, where the host structure forms a solid solution with Li within a certain Li composition range, or by a two-phase reaction, where a first-order phase transition is induced as Li is (de)intercalated. A single-phase reaction, which proceeds via a continuous structural change and avoids nucleation of a second phase, is generally considered to be important for fast reaction kinetics and is thought to be more favourable than a two-phase reaction for long-term capacity retention of the battery. Recent studies have identified a non-equilibrium single-phase transition mechanism in nanoparticulate $\mathrm{LiFePO}_{4}$ (ref. 1 and 2) and $\mathrm{LiNi}_{1 / 2} \mathrm{Mn}_{3 / 2} \mathrm{O}_{4},{ }^{3}$ electrode materials that are generally thought to transform via a twophase mechanism at low cycling rates. The possibility that a two-phase material can transform via a single-phase mechanism under non-equilibrium conditions opens up new avenues for the search of new electrode compounds and begs the

Department of Chemistry, University of Cambridge, Lensfield Road, CB2 1EW, UK. E-mail:cpg27@cam.ac.uk

$\dagger$ Electronic supplementary information (ESI) available. See DOI: $10.1039 /$ c6ta00673f question as to how prevalent this phenomenon is in compounds that exhibit a thermodynamic Li miscibility gap (between two compounds with different Li stoichiometries). To complement previous studies, which have only explored compounds that do not involve a change in crystal symmetry between the two end member phases, this work investigates the phase transition of anatase $\mathrm{TiO}_{2}$, which transforms from tetragonal to orthorhombic symmetry upon Li intercalation.

Anatase, $\mathrm{TiO}_{2}$, is used as an anode material for lithium ion batteries and, in theory, can accommodate a maximum of $1 \mathrm{Li}$ per formula unit (f.u.). Initial Li intercalation into anatase $\mathrm{TiO}_{2}$ from $z=0$ to $0.025\left(z\right.$ in $\left.\mathrm{Li}_{z} \mathrm{TiO}_{2}\right)$ proceeds by a single-phase, solid solution reaction. ${ }^{4}$ When $\mathrm{Li}$ is further intercalated, there is a two-phase reaction in the composition range $0.025<z<0.5(z$ in $\mathrm{Li}_{z} \mathrm{TiO}_{2}$ ) between tetragonal $\mathrm{Li}_{a \approx 0.025} \mathrm{TiO}_{2}\left(\mathrm{I}_{1} /\right.$ amd, no. 141 , Fig. 1A), ${ }^{5}$ denoted as the $\alpha-\mathrm{TiO}_{2}$ phase, and orthorhombic $\mathrm{Li}_{b \approx 0.5} \mathrm{TiO}_{2}$ (Imma, no. 74 , Fig. 1B), ${ }^{6}$ denoted as the $\beta-\mathrm{Li}_{0.5} \mathrm{TiO}_{2}$ phase. Further intercalation for $z>0.5$ is kinetically restricted by very slow $\mathrm{Li}$ ion diffusion, ${ }^{7,8}$ and as a result, transformation to $\mathrm{LiTiO}_{2}\left(\mathrm{IL}_{1} / \mathrm{amd}\right.$, Fig. 1C), denoted as $\gamma-\mathrm{LiTiO}_{2}$, is only observed for very small nanoparticles $(\sim 7 \mathrm{~nm})$ and on the surface layer of larger particles at room temperature. ${ }^{4}$ The thermodynamics of the system are also dependent on the particle size: for particles larger than $50 \mathrm{~nm}$, both the $\alpha-\mathrm{TiO}_{2}$ and $\beta-\mathrm{Li}_{0.5} \mathrm{TiO}_{2}$ phases can coexist in a single particle; for particles smaller than $50 \mathrm{~nm}$, such phase coexistence is not stable, and for overall Li stoichiometries of $0.025<z<0.5$ for the whole powder or electrode each individual crystallite is composed entirely of either the $\alpha$ - 

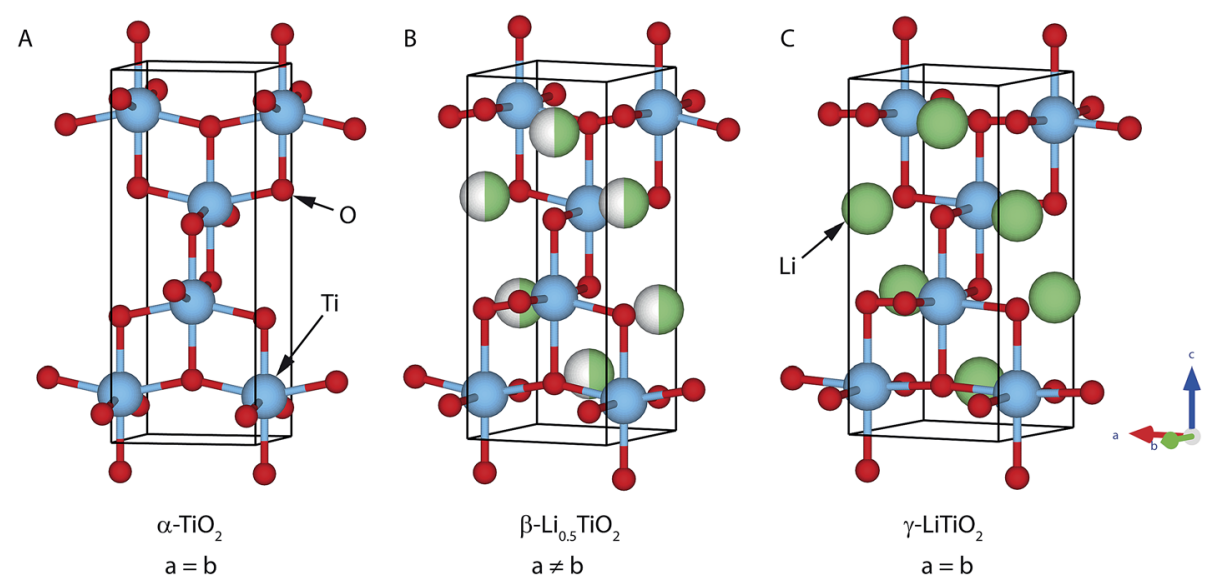

Fig. 1 The crystal structures of (A) tetragonal $\alpha-\mathrm{TiO}_{2}$, (B) orthorhombic $\beta-\mathrm{Li}_{0.5} \mathrm{TiO}_{2}$ and (C) tetragonal $\gamma$ - $\mathrm{LiTiO}_{2}$. The half-filled green/white spheres correspond to sites that are randomly occupied by either a Li or a vacancy with equal probability.

$\mathrm{TiO}_{2}$ or the $\beta-\mathrm{Li}_{0.5} \mathrm{TiO}_{2}$ phase. ${ }^{4}$ The effect of particle size on the reaction mechanism at a very low rate $(\mathrm{C} / 120)$ was recently investigated by in situ XRD. ${ }^{9}$ It was found that both small (15 $\mathrm{nm})$ and large $(130 \mathrm{~nm})$ particles react via the sequential reaction of particles, i.e., the so-called domino-cascade mechanism proposed originally for nanoparticles of $\mathrm{LiFePO}_{4}{ }^{10}$ The same study, despite being carried out at a low rate, also reveals a nonequilibrium nature for the transition between $\alpha-\mathrm{TiO}_{2}$ and $\beta$ $\mathrm{Li}_{0.5} \mathrm{TiO}_{2}$ : the Li content of $\alpha-\mathrm{TiO}_{2}$ and $\beta-\mathrm{Li}_{0.5} \mathrm{TiO}_{2}$ measured during the transition process of $\mathrm{TiO}_{2} \rightarrow \mathrm{Li}_{0.5} \mathrm{TiO}_{2}$ being different than the Li content measured under equilibrium at the same state of overall lithiation, the effect being more pronounced for the $15 \mathrm{~nm}$ particles. Hence, it would be interesting to explore whether the deviation from the equilibrium $\mathrm{Li}$ composition could be large enough at high rates to achieve a continuous (2nd-order) phase transition between $\alpha-\mathrm{TiO}_{2}$ and $\beta-\mathrm{Li}_{0.5} \mathrm{TiO}_{2}$. To this end, the phase transition of anatase $\mathrm{TiO}_{2}$ during electrochemical cycling under different cycling rates and temperatures is investigated here by using in situ synchrotron XRD. By following the changes in the Bragg peaks of both $\alpha-\mathrm{TiO}_{2}$ and $\beta-\mathrm{Li}_{0.5} \mathrm{TiO}_{2}$ phases during one discharge-charge cycle, we find the nature of the phase transition remains first order regardless of the cycling conditions tested here. Our study suggests the first-order phase transition is more energetically favourable than an overpotential-driven second-order phase transition.

\section{Experimental}

\section{Materials and electrode preparation}

The $25 \mathrm{~nm}$ and $100 \mathrm{~nm} \mathrm{TiO}_{2}$ powders were purchased from Sigma Aldrich. The electrode was prepared with a high proportion of carbon additives, to improve the electrochemical performance of the active material at high rates (by increasing the electronic conductivity). For a typical electrode, $3 \mathrm{mg}$ of the active material powder was mixed with Super P carbon (Alfa Aesar), carbon black (Vulcan XC-72, Cabot Corporation) and polytetrafluoroethylene (PTFE) binder (Sigma-Aldrich) in the mass ratio $3: 3: 3: 1$ and was pressed (1.6-1.8 ton) into a pellet of $13 \mathrm{~mm}$ in diameter.

\section{Laboratory XRD measurement}

The as-purchased anatase $\mathrm{TiO}_{2}$ samples were measured at room temperature on a Panalytical Empyrean diffractometer using $\mathrm{Cu}$ $\mathrm{K} \alpha$ radiation. Whole powder pattern fitting was performed with TOPAS software. The peak profile was modelled by the isotropic size broadening. The Voigt peak shape (convolution of Lorentzian and Gaussian peak shape) is used to describe the isotropic size broadening, and $2 \theta$ dependence of the peak width is given by

$$
H_{\text {iso }}=0.9 \lambda /(L \cos (\theta))
$$

where $H_{\text {iso }}$ is the full width at half maximum (FWHM) of the Voigt profile, $\lambda$ is the wavelength of the incident beam, and $L$ is the refined parameter corresponding to the average particle size.

\section{In situ XRD measurement}

The electrode pellet was assembled into the AMPIX cell ${ }^{11}$ with $\mathrm{Li}$ foil as the anode, glass fibre as the separator and $1 \mathrm{M} \mathrm{LiPF}_{6}$ in $1: 1$ ethylene carbonate/dimethyl carbonate (Tomiyama Pure Chemical Industries) as the liquid electrolyte. For high temperature electrochemical cycling, the cell was heated up with a heating tape whose temperature was set to $80{ }^{\circ} \mathrm{C}$ by a thermostat. In situ synchrotron XRD measurements were performed in transmission geometry at beamline 17-BM of the Advanced Photon Source at Argonne National Laboratory (wavelength $0.72779 \AA$ ̊, $500 \mu \mathrm{m}$ diameter beam). An area detector (PerkinElmer) consisting of $2048 \times 2048$ pixels of $200 \mu \mathrm{m} \times 200 \mu \mathrm{m}$ in size was used and was placed $400 \mathrm{~mm}$ away from the AMPIX cell. The same electrode was used for the in situ measurement at different cycling rates, with measurements taken in the order from low to high rate. The data collection time of each sequential pattern for 1C, 2C, 5C, 10C and 20C cycling rates was $30 \mathrm{~s}, 12 \mathrm{~s}, 6$ $\mathrm{s}, 3 \mathrm{~s}$, and $3 \mathrm{~s}$, respectively, which corresponds to a change of 
$0.004 \mathrm{Li}, 0.003 \mathrm{Li}, 0.004 \mathrm{Li}, 0.004 \mathrm{Li}$ and $0.008 \mathrm{Li}$, respectively, per formula unit (f.u.) of $\mathrm{TiO}_{2}$ during the collection of each pattern. The C-rate is calculated based on the theoretical capacity of $0.5 \mathrm{Li}$ insertion per f.u., which is $168 \mathrm{~mA} \mathrm{~h} \mathrm{~g}{ }^{-1}$. $\mathrm{LaB}_{6}$ powder was measured to obtain the instrumental broadening profile.

Rietveld refinements were performed with TOPAS software package $^{12}$ in the $2 \theta$ range $10.3-35.5^{\circ}$. The background was modelled by 4 asymmetrical pseudo-Voigt peaks at positions $\sim 11.7^{\circ}, \sim 20.1^{\circ}, \sim 25.0^{\circ}, \sim 34.8^{\circ}$, respectively, full width at half maximum (FWHM), intensity, shape parameter being refined, to account for the diffraction background intensity from glassy carbon, glass fibre separator and the liquid electrolyte, on top of the function $B / 2 \theta$, where $B$ was refined. Two phases corresponding to $\alpha-\mathrm{TiO}_{2}\left(\right.$ I $4_{1} /$ amd $)$ and $\beta-\mathrm{Li}_{0.5} \mathrm{TiO}_{2}$ (Imma) were included in the refinement. The scale factors, unit cell parameters, atomic coordinates and isotropic atomic displacement parameters (ADP) for $\mathrm{Ti}$ and $\mathrm{O}$ atoms were refined. Ti and $\mathrm{O}$ atoms in both phases were constrained to have the same ADP for each atomic species. The peak profile was modelled by the convolution of isotropic size broadening as described in eqn (1) with anisotropic strain-like broadening (both Lorentzian and Gaussain).

The $2 \theta$ dependence of the anisotropic strain-like broadening is described by

$$
H_{\text {aniso }}=\Sigma_{i j} C_{i j} Y_{i j} \tan (\theta)
$$

where $H_{\text {aniso }}$ is the FWHM of the Voigt peak profile, $Y_{i j}$ is the symmetrised spherical harmonics, ${ }^{13}$ and $C_{i j}$ are the refined parameters. Since the peak broadening was modelled empirically to obtain a good refinement, no microstructural information about the sample was obtained.

\section{Results and discussion}

\section{Particle size and electrochemistry of anatase $\mathrm{TiO}_{2}$}

The scanning electron microscope (SEM) images of the aspurchased $\mathrm{TiO}_{2}$ powder, specified as $100 \mathrm{~nm}$ and $25 \mathrm{~nm}$, respectively, are shown in Fig. 2A and B. To confirm the particle size of the two samples, Pawley fitting against the XRD patterns of the as-purchase samples was performed to extract the particle size, and the results are shown in Fig. 2C and D for the $100 \mathrm{~nm}$ and the $25 \mathrm{~nm}$ samples, respectively. The refined average particle sizes (91 $\pm 13 \mathrm{~nm}$ and $24.8 \pm 0.5 \mathrm{~nm}$ ) are in good agreement (within errors) with the specification given by the supplier. (Analysis on the particle size distribution can be found in Fig. S1. $\dagger$ ) Henceforward, the two $\mathrm{TiO}_{2}$ samples are referred to by the size specified by the supplier, i.e. $100 \mathrm{~nm}$ and $25 \mathrm{~nm}$, respectively.

In situ XRD measurements were conducted for both $\mathrm{TiO}_{2}$ samples at cycle rates of $1 \mathrm{C}, 2 \mathrm{C}$ and $5 \mathrm{C}$ at room temperature and at cycle rates of $5 \mathrm{C}, 10 \mathrm{C}$ and $20 \mathrm{C}$ at $80{ }^{\circ} \mathrm{C}$. The same electrode comprised of $25 \mathrm{~nm}$ particles was used for both room temperature and $80{ }^{\circ} \mathrm{C}$ cycles, while two electrodes made with $100 \mathrm{~nm}$ particles were used for room temperature and $80^{\circ} \mathrm{C}$ cycling. Cycles were carried out in the order of increasing rates at each
A

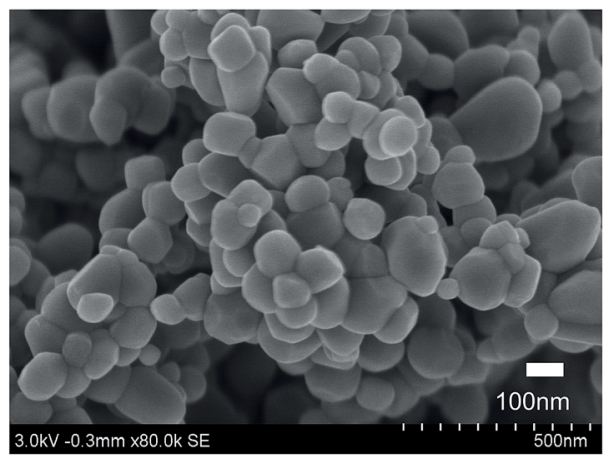

C

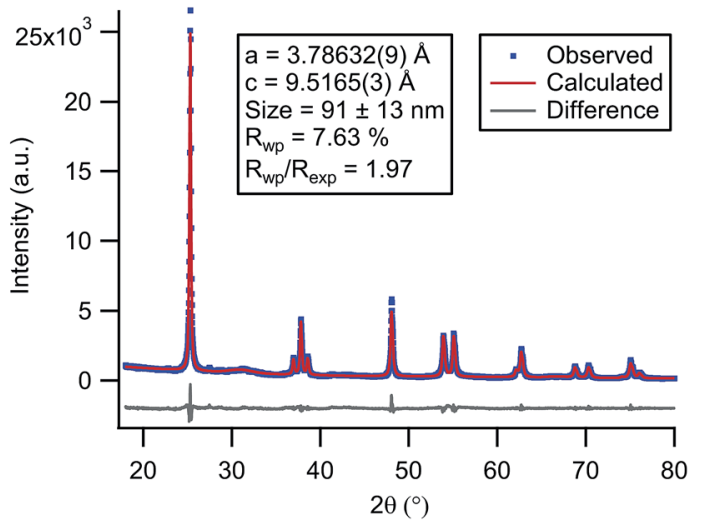

B

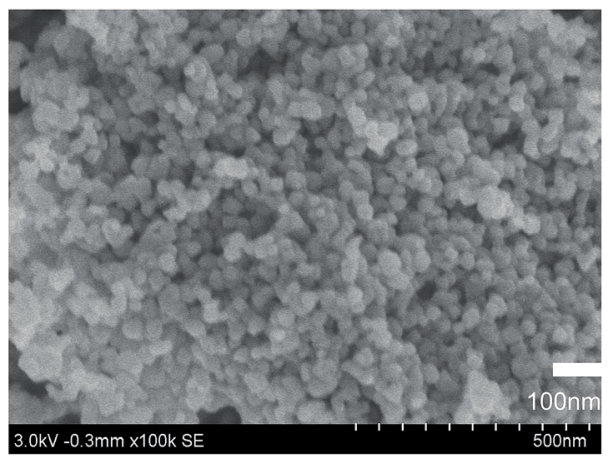

D

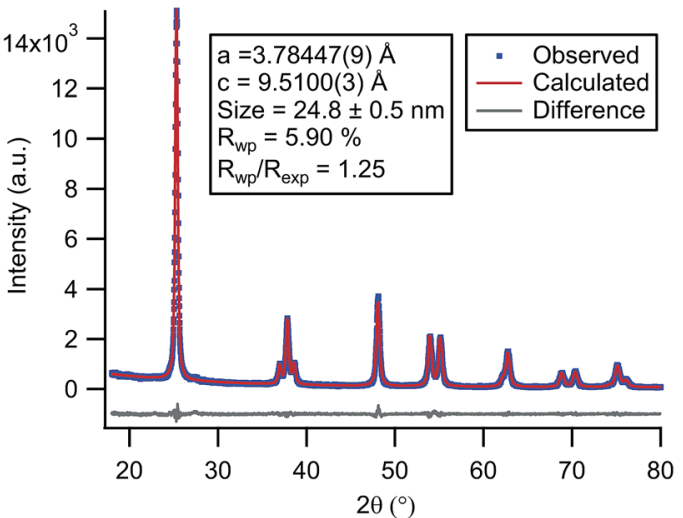

Fig. 2 SEM images obtained for (A) $100 \mathrm{~nm}$ and (B) $25 \mathrm{~nm}$ anatase $\mathrm{TiO}_{2}$ samples. Pawley fitting results against the XRD patterns of the (C) $100 \mathrm{~nm}$ and (D) $25 \mathrm{~nm}$ anatase $\mathrm{TiO}_{2}$ samples. 
temperature, for example, $1 \mathrm{C}, 2 \mathrm{C}$ and $5 \mathrm{C}$ cycles were carried out sequentially at room temperature. For $25 \mathrm{~nm}$ particles, cycling at $80{ }^{\circ} \mathrm{C}$ was performed after all the cycling at room temperature had been completed. Discharge and charge were limited to the voltage window 1.0-3.5 V, except for the room temperature $1 \mathrm{C}$ and $2 \mathrm{C}$ cycling of the $25 \mathrm{~nm}$ particles, where the low cut-off voltage was accidently set to $1.2 \mathrm{~V}$. The voltage profiles obtained during the in situ XRD experiment are shown in Fig. 3. The $x$ axis corresponds to the total Li inserted or removed per f.u. of $\mathrm{TiO}_{2}$ and is calculated from the measured experimental capacity assuming $100 \%$ coulombic efficiency and is denoted by $x$; the $\mathrm{Li}$ composition of each phase is denoted by $z$.

For $100 \mathrm{~nm}$ particles at $1 \mathrm{C}$ cycling at room temperature (Fig. 3A), the discharge voltage profile is consistent with previous report: ${ }^{14}$ a steep drop in voltage is followed by a voltage plateau at $1.7 \mathrm{~V}$ between $x=0.05$ and 0.25 , corresponding to the transition from $\alpha-\mathrm{TiO}_{2}$ to $\beta-\mathrm{Li}_{0.5} \mathrm{TiO}_{2}$. The sloping voltage profile towards the end of discharge (from $x=0.3$ to $0.45 \mathrm{Li}$ ) is tentatively attributed to an increased voltage polarisation due to the slow reaction kinetics associated with the transformation of the last fraction of $\alpha-\mathrm{TiO}_{2}$ to $\beta$ - $\mathrm{Li}_{0.5} \mathrm{TiO}_{2}$, and electrolyte decomposition at low voltages ${ }^{15,16}$ to form a protective layer of solid electrolyte interface (SEI). Further Li insertion exceeding $\mathrm{Li}_{0.5} \mathrm{TiO}_{2}$ has also been seen by some authors. ${ }^{17,18}$ Except for the irreversible SEI formation, the aforementioned process is reversed on charge. The small voltage bump seen on charge at $x=0.57$ is associated with a kinetic barrier, such as nucleation of a second phase or the slow Li diffusion in $\gamma$ $\mathrm{LiTiO}_{2}$, which may form as a surface layer. The voltage profiles under other cycling conditions exhibit similar behaviour.

\section{Phase evolution of anatase $\mathrm{TiO}_{2}$ under various conditions}

Image plots of the time-resolved in situ XRD patterns for the evolution of the (024) reflection of $\alpha-\mathrm{TiO}_{2}$ and the (204) reflection of $\beta-\mathrm{Li}_{0.5} \mathrm{TiO}_{2}$ during high rate cycling at room temperature are shown in Fig. $4 \mathrm{~A}-\mathrm{C}$ for $100 \mathrm{~nm}$ particles and Fig. 4D-F for $25 \mathrm{~nm}$ particles. (024) and (204) are symmetry equivalent reflections in tetragonal $\alpha-\mathrm{TiO}_{2}$, but not in orthorhombic $\beta-\mathrm{Li}_{0.5} \mathrm{TiO}_{2}$. If the transition from the tetragonal to the orthorhombic phase is continuous, one would expect to observe, in the in situ XRD patterns, the branching of the (024) reflection into two reflections, (204) and (024), and then the continuous shift of these reflections towards the $2 \theta$ values of the $\beta-\mathrm{Li}_{0.5} \mathrm{TiO}_{2}$ (204) and (024) reflections, respectively. For clarity, the $(024)$ reflection of $\beta-\mathrm{Li}_{0.5} \mathrm{TiO}_{2}$, which appears at a lower $2 \theta$ angle but overlaps with other peaks, is not shown. On discharging the $100 \mathrm{~nm}$ particles at a cycle rate of $1 \mathrm{C}$ (Fig. 4A), the (024) reflection of $\alpha-\mathrm{TiO}_{2}$ shifts to a lower $2 \theta$ angle (0-0.07 overall cycled $\mathrm{Li}$ per f.u.) at the beginning of discharge, indicating an increase in the Li content of $\alpha-\mathrm{TiO}_{2}$ via a single-phase reaction; further discharge shows a characteristic two-phase reaction, where the (204) reflection of $\beta-\mathrm{Li}_{0.5} \mathrm{TiO}_{2}$ grows at the expense of the (024) reflection of $\alpha-\mathrm{TiO}_{2}$. On discharge, the (204) reflection of $\beta-\mathrm{Li}_{0.5} \mathrm{TiO}_{2}$ decreases in intensity and the (024) reflection of $\alpha-\mathrm{TiO}_{2}$ is restored. A similar evolution of the (024) reflection of $\alpha-\mathrm{TiO}_{2}$ is observed for the $100 \mathrm{~nm}$ particles at cycle rates of $2 \mathrm{C}$ and $5 \mathrm{C}$, as shown in Fig. $4 \mathrm{~B}$ and $\mathrm{C}$, respectively; however, due to the limited extent of formation of $\beta-\mathrm{Li}_{0.5} \mathrm{TiO}_{2}$ on discharging at higher rates, the intensity of the (204) reflection of $\beta-\mathrm{Li}_{0.5} \mathrm{TiO}_{2}$ becomes very weak at $2 \mathrm{C}$, as reflected by the single contour level corresponding to $\sim 9 \%$ maximum intensity of the image (Fig. 4B) seen for this reflection; it is barely visible at 5C, where the intensity of the $\beta-\mathrm{Li}_{0.5} \mathrm{TiO}_{2}$ (204) reflection is less than $\sim 9 \%$ (Fig. 4C). The diffraction patterns shown in Fig. 4D-F are qualitatively similar to those of the $100 \mathrm{~nm}$ particles and also display features of the two-phase reactions. The $25 \mathrm{~nm}$ particles show improved kinetics as indicated by the higher fraction of
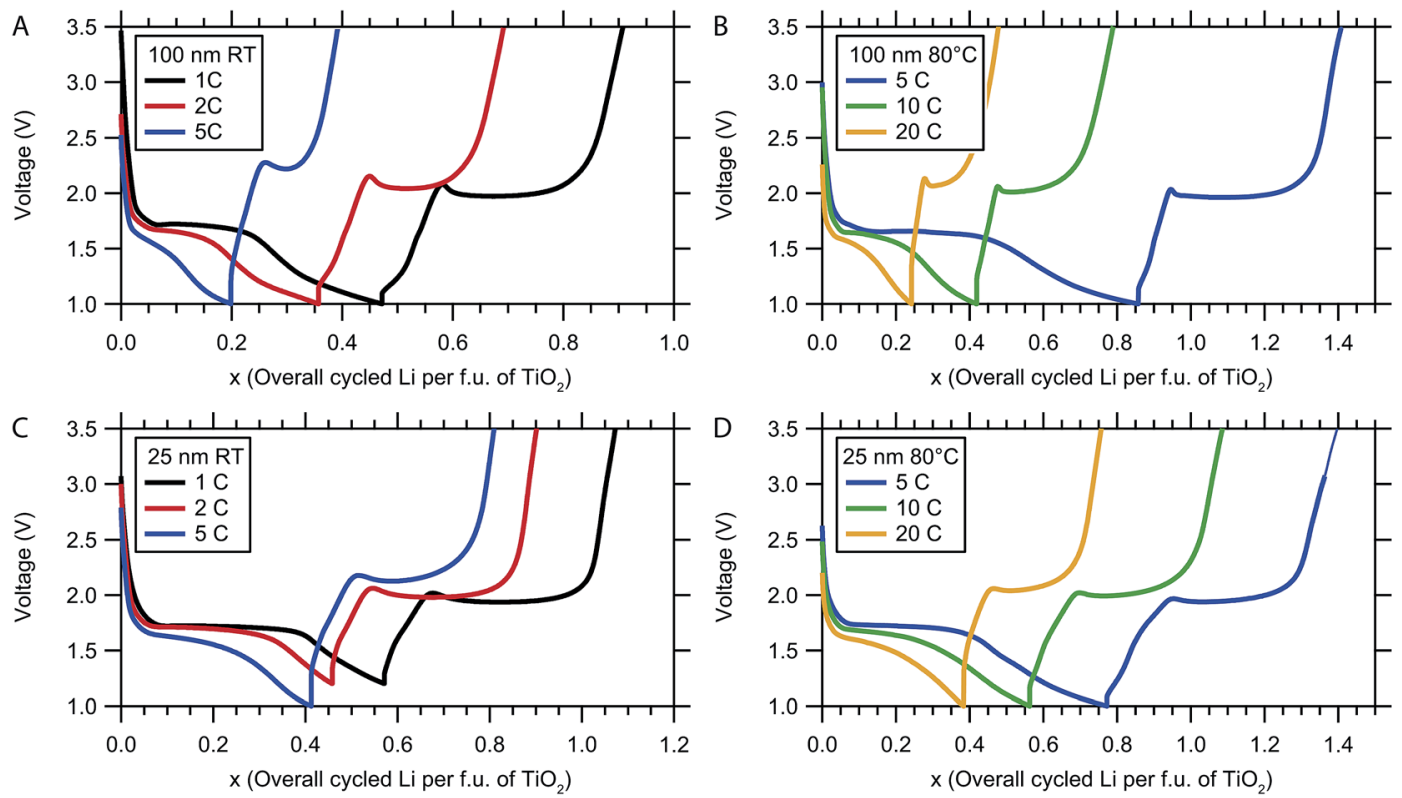

Fig. 3 Voltage profiles for the discharge-charge cycles performed during the in situ XRD experiment. (A) Room temperature (RT) and (B) $80{ }^{\circ} \mathrm{C}$ cycling for $100 \mathrm{~nm}$ particles. (C) Room temperature and (D) $80^{\circ} \mathrm{C}$ cycling for $25 \mathrm{~nm}$ particles. 

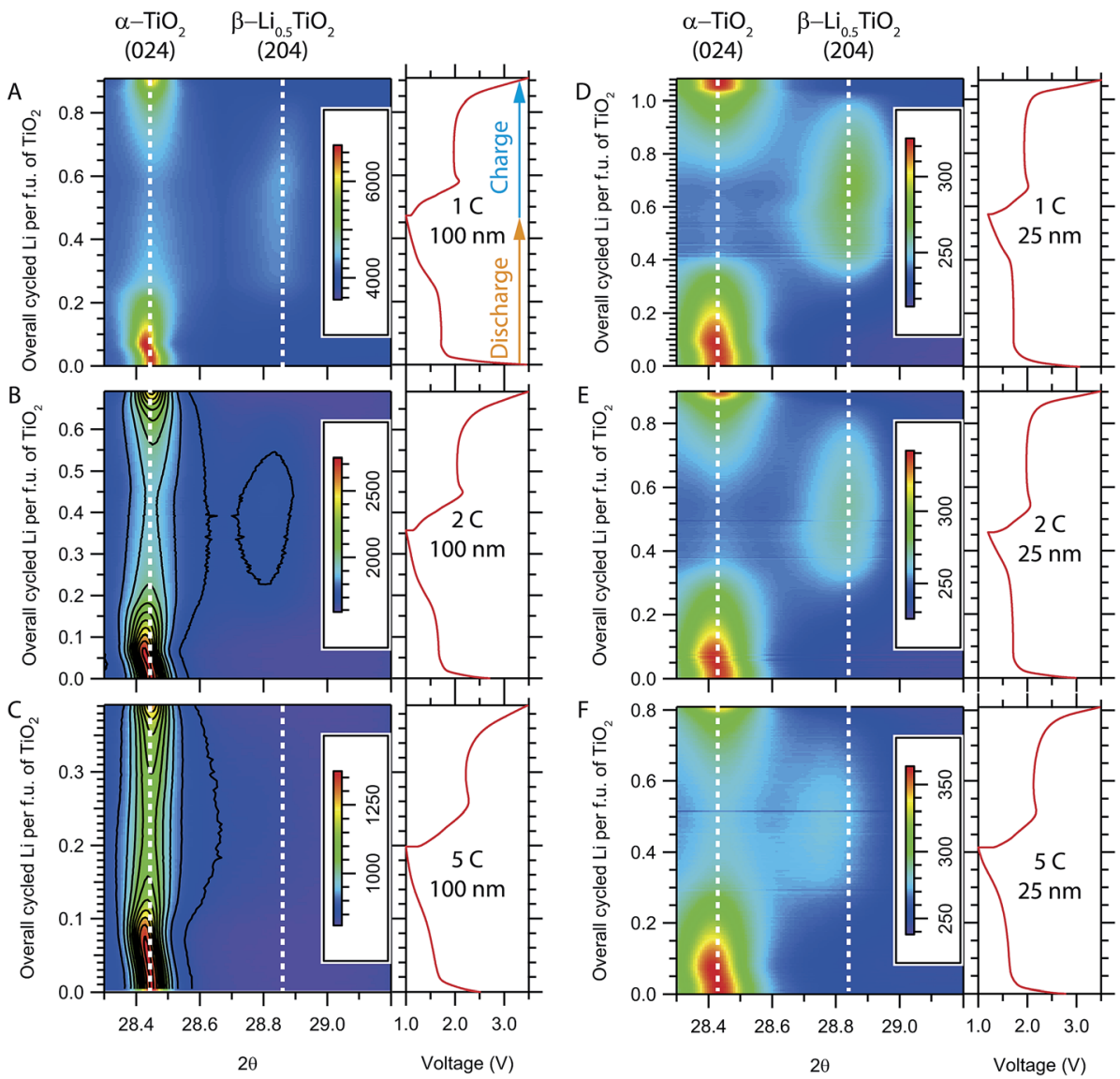

Fig. 4 Image plots showing the time evolution of the in situ XRD patterns at room temperature for (A-C) $100 \mathrm{~nm}$ and (D-F) $25 \mathrm{~nm}$ TiO 2 particles at various cycling rates. The intensity scale is shown by the colour bar. The electrochemical profile is shown in the graph to the right of each image. Only the $2 \theta$ region for the (024) reflection of $\alpha-\mathrm{TiO}_{2}$ and the (204) reflection of $\beta-\mathrm{Li}_{0.5} \mathrm{TiO}_{2}$ is shown. The (204) reflection of $\beta$ - $\mathrm{Li}$. ${ }_{0.5} \mathrm{TiO}{ }_{2}$ is barely visible in $\mathrm{B}$ and $\mathrm{C}$ due to the formation of a very limited amount of $\beta$ - $\mathrm{Li}_{0.5} \mathrm{TiO}_{2}$; the equally-spaced intensity contours (11 levels in total) are drawn in black in these figures to aid visual inspection.

the $\beta-\mathrm{Li}_{0.5} \mathrm{TiO}_{2}$ formed and the higher discharge capacity at the end of discharge in comparison to the $100 \mathrm{~nm}$ particles at equivalent rate: for example, the discharge capacity of $25 \mathrm{~nm}$ particles at $5 \mathrm{C}$ corresponds to the insertion of $0.4 \mathrm{Li}$ per f.u. as opposed to $0.2 \mathrm{Li}$ for $100 \mathrm{~nm}$ particles at the same rate.

Since the (dis)charge process at room temperature terminates prematurely at higher rates $(\geq 5 \mathrm{C})$, to probe the phase transition at rates above $5 \mathrm{C}$, electrochemical cycling was performed at an elevated temperature $\left(\sim 80^{\circ} \mathrm{C}\right)$ to improve the Li diffusion and the reaction kinetics; the corresponding in situ XRD patterns are shown in Fig. 5. While there is a noticeable improvement in the rate performance of both $100 \mathrm{~nm}$ and $25 \mathrm{~nm}$ particles with the formation of a substantial amount of $\beta-\mathrm{Li}_{0.5} \mathrm{TiO}_{2}$ at the end of the $20 \mathrm{C}$ discharge, the XRD patterns still exhibit characteristic twophase behaviour for both particles sizes. Visual inspection of the in situ XRD patterns suggest the delithiation undergoes the same mechanism as lithiation, therefore, only the analysis and discussion of the lithiation process are presented in this article.

\section{Evolution of lattice parameters and phase fractions}

Rietveld refinements were carried out to follow the evolution of the $\alpha-\mathrm{TiO}_{2}$ and $\beta-\mathrm{Li}_{0.5} \mathrm{TiO}_{2}$ lattice parameters and capture any quantitative differences in the phase transition between the various cycling conditions. Typical fitting patterns and $R_{\mathrm{wp}}$ factors can be found in Fig. S2 and S3, $\uparrow$ respectively. The refined lattice parameters as a function of the overall $\mathrm{Li}$ composition determined from the electrochemistry during discharge are shown in Fig. 6. The evolution of the $\alpha-\mathrm{TiO}_{2}$ lattice parameters exhibits two different regimes: (i) an initial steep increase (decrease) of the $a(c)$ lattice parameter within the first $\sim 0.1$ overall Li insertion, followed by (ii) a much gradual increase (decrease) of the $a(c)$ lattice parameter until the end of discharge. Regime (i) is in line with the single-phase reaction within the limited Li solubility, where the insertion of Li only changes the Li composition of the $\alpha-\mathrm{TiO}_{2}$ phase. Upon entering regime (ii), the $\beta-\mathrm{TiO}_{2}$ phase starts to form after the $\alpha-\mathrm{TiO}_{2}$ phase becomes saturated with $\mathrm{Li}$.

The Li composition of each phase can be interpolated under the assumption of Vegard's law; here, it is based on the interpolation of the $c$ lattice parameter since it has been shown to vary linearly across the stoichiometries of $\alpha-\mathrm{TiO}_{2}, \beta-\mathrm{Li}_{0.5} \mathrm{TiO}_{2}$, and $\gamma-\mathrm{LiTiO}_{2}$ (ref. 4) (Fig. S4†). The evolution of the Li composition of each phase during discharge is shown in Fig. 7, where the dashed grey lines indicate the thermodynamic Li solubility 

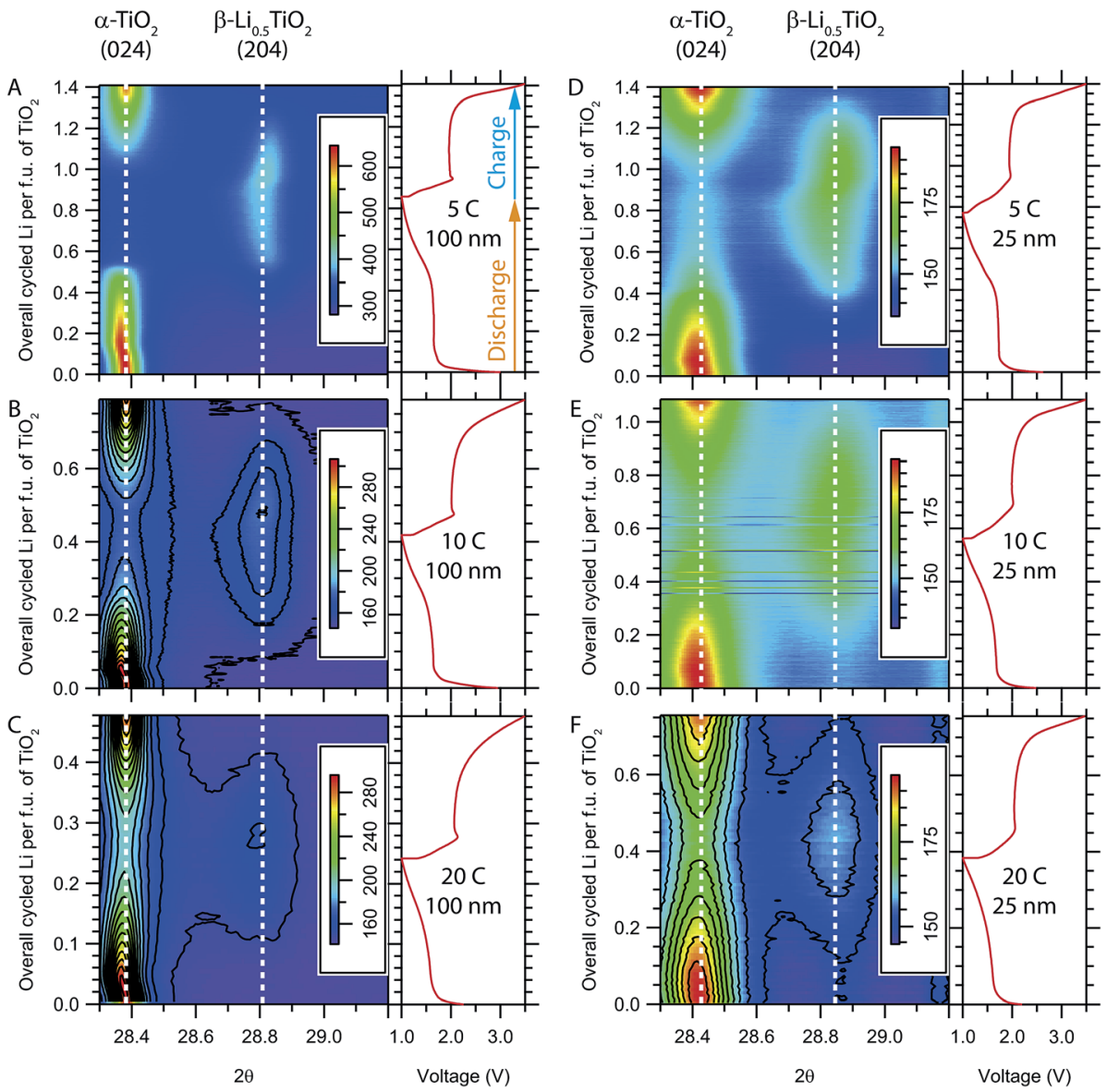

Fig. 5 Image plots showing the time evolution of the in situ XRD patterns collected at elevated temperature $\left(\sim 80^{\circ} \mathrm{C}\right)$ for $(A-C) 100 \mathrm{~nm}$ and $(\mathrm{D}-\mathrm{F})$ $25 \mathrm{~nm} \mathrm{TiO} 2$ particles at various cycling rates. The intensity scale is shown by the colour bar. The electrochemical profile is shown in the graph to the right of each image. The $2 \theta$ region for the (024) reflection of $\alpha-\mathrm{TiO}_{2}$ and the (204) reflection of $\beta-\mathrm{Li}_{0.5} \mathrm{TiO}_{2}$ is shown. Equally spaced intensity contours (11 levels in total) are drawn in black in B, C and $F$ to aid visual inspection.

limits determined from neutron diffraction studies of $120 \mathrm{~nm}$ particles. ${ }^{4}$ The Li composition of the saturated $\alpha-\mathrm{TiO}_{2}$ (see for example in Fig. 7A for the discharge processes of $100 \mathrm{~nm}$ at room temperature at the overall $\mathrm{Li}$ composition of $\sim 0.07$ ) and that of the emerging $\beta-\mathrm{Li}_{0.5} \mathrm{TiO}_{2}$ phase (at the overall $\mathrm{Li}$ composition of $\sim 0.15$ ) exceeds the thermodynamic Li solubility limit. Furthermore, as also shown in Fig. 7A, the Li composition of the saturated $\alpha-\mathrm{TiO}_{2}$ phase (at the overall Li composition of 0.07-0.1) increases progressively with cycle rate: the maximum $\mathrm{Li}$ composition of the $\alpha-\mathrm{TiO}_{2}$ phase before the formation of the $\beta-\mathrm{TiO}_{2}$ phase is found to be $z=0.042,0.045$, and 0.054 for $1 \mathrm{C}$, $2 \mathrm{C}$ and $5 \mathrm{C}$, respectively, where $z$ is the $\mathrm{Li}$ composition of $\mathrm{Li}_{z^{-}}$ $\mathrm{TiO}_{2}$. This rate-dependent solubility is similar to what was observed ${ }^{2}$ and predicted ${ }^{19}$ for $\mathrm{LiFePO}_{4}$ at moderately high rates, and is attributed to the overpotential induced by the high current. In comparison, the same, yet less pronounced, rateinduced solubility is observed at higher temperature: for example, for the $100 \mathrm{~nm}$ particles cycled at $5 \mathrm{C}$ at $80^{\circ} \mathrm{C}$ (Fig. 7B), the maximum $\mathrm{Li}$ composition of the $\alpha-\mathrm{TiO}_{2}$ phase before the $\beta$ $\mathrm{Li}_{0.5} \mathrm{TiO}_{2}$ phase is formed is less than that at room temperature $\left(\mathrm{Li}_{0.035} \mathrm{TiO}_{2}\right.$ is observed at an overall $\mathrm{Li}$ composition of $\sim 0.17$ at $80{ }^{\circ} \mathrm{C}$, whereas $\mathrm{Li}_{0.054} \mathrm{TiO}_{2}$ is seen at an overall $\mathrm{Li}$ composition of $0.1 \mathrm{in} \mathrm{Fig.} 7 \mathrm{~A})$. The $\mathrm{Li}$ composition of the emerging $\beta-\mathrm{Li}_{0.5} \mathrm{TiO}_{2}$ phase is also closer to the thermodynamic limit than that at room temperature. A similar observation is also made for the 25 $\mathrm{nm}$ particles at $80^{\circ} \mathrm{C}$ in Fig. 7D. The Li composition of $\alpha-\mathrm{TiO}_{2}$ increases even after the appearance of $\beta-\mathrm{Li}_{0.5} \mathrm{TiO}_{2}$, especially at the end of the voltage plateau. For example, in Fig. 7A the Li composition of $\alpha-\mathrm{TiO}_{2}$ during $1 \mathrm{C}$ discharge increases substantially after inserting more than $0.2 \mathrm{Li}$ per f.u., which coincides with the end of the voltage plateau. As more $\alpha-\mathrm{TiO}_{2}$ is transformed to $\beta-\mathrm{Li}_{0.5} \mathrm{TiO}_{2}$, transformation of the residual $\alpha-\mathrm{TiO}_{2}$ to $\beta-\mathrm{Li}_{0.5} \mathrm{TiO}_{2}$ becomes more difficult and requires a higher overpotential, which then allows more $\mathrm{Li}$ to be inserted in $\alpha-\mathrm{TiO}_{2}$.

The less pronounced rate-induced Li solubility at the higher temperature reflects the kinetic nature of this phenomenon, which is associated with the finite Li diffusivity in the $\alpha$-TiO and $\beta-\mathrm{Li}_{0.5} \mathrm{TiO}_{2}$ phases: a system not subject to kinetic limitations will always be found in its thermodynamic equilibrium state, and the $\mathrm{Li}$ composition of the $\alpha-\mathrm{TiO}_{2}$ and $\beta-\mathrm{Li}_{0.5} \mathrm{TiO}_{2}$ phases will not exceed their thermodynamic solubilities if the $\mathrm{Li}$ diffusion, which has been found to be limited by the $\mathrm{Li}$ migration across the $\alpha-\mathrm{TiO}_{2} / \beta-\mathrm{Li}_{0.5} \mathrm{TiO}_{2}$ interface, ${ }^{20}$ is infinitely fast. As the diffusion of $\mathrm{Li}$ becomes faster with increasing temperature, the $\mathrm{Li}$ solubilities of $\alpha-\mathrm{TiO}_{2}$ and $\beta-\mathrm{Li}_{0.5} \mathrm{TiO}_{2}$ will approach their thermodynamic limits. 


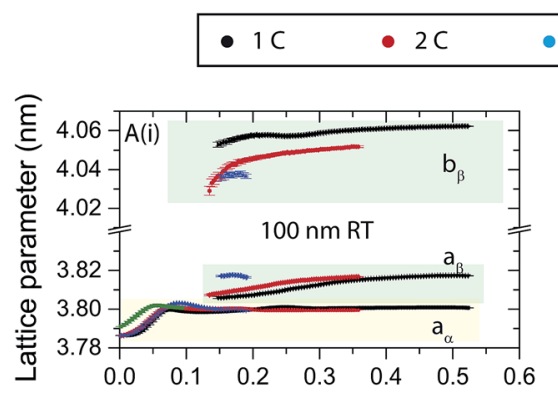

$5 \mathrm{C} \quad \cdot 10 \mathrm{C} \quad \cdot 20 \mathrm{C}$
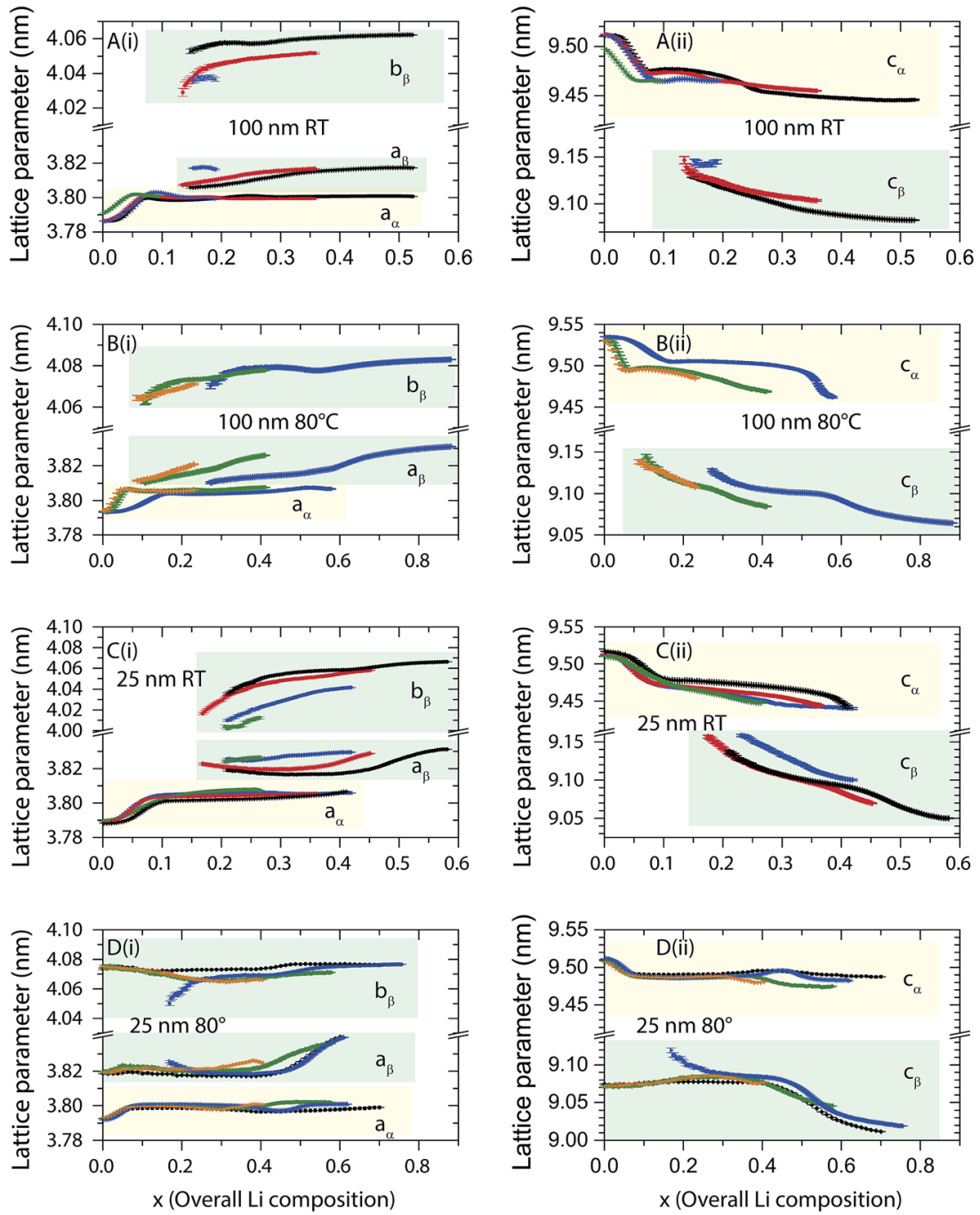

Fig. 6 Lattice parameters of both $\alpha-\mathrm{TiO}_{2}$ (highlighted in yellow and labelled with the subscript $\alpha$ ) and $\beta$ - $\mathrm{Li}_{0.5} \mathrm{TiO}_{2}$ (highlighted in green and labelled with the subscript $\beta$ ) phases obtained from Rietveld refinements for both the room temperature (RT) and the $80{ }^{\circ} \mathrm{C}$ discharge processes.

\section{Microstructural evolution of anatase $\mathrm{TiO}_{2}$ particles during discharge}

Although the in situ XRD patterns clearly show the presence of only two phases, it is not obvious as to what occurs on the particle level: does the reaction proceed particle by particle or simultaneously in all particles? To answer this question, microstructural analysis was performed based on the FWHM of the (024), (116) and (220) reflections of the $\alpha-\mathrm{TiO}_{2}$ phase and the (011), (204) and (220) reflections of the $\beta-\mathrm{Li}_{0.5} \mathrm{TiO}_{2}$ phase. These reflections were selected because there is no or only a small amount of overlap with other reflections, in order to minimise ambiguity and correlation in the peak fitting process. The results from fitting individual reflections including the FWHM and the domain size calculated from Scherrer formula, and the phase fractions obtained from Rietveld refinements are presented and discussed below.

\section{$100 \mathrm{~nm} \mathrm{TiO}_{2}$ particles}

The fitting results for $100 \mathrm{~nm}$ particles are shown in Fig. 8 and 9 for the discharge at room temperature and $80{ }^{\circ} \mathrm{C}$, respectively. Typical fitting patterns can be found in Fig. S5. $\dagger$ For $100 \mathrm{~nm}$ particles cycled at a rate of $1 \mathrm{C}$ at room temperature (Fig. $8 \mathrm{~A}(\mathrm{i})$ ), the (024), (116) and (220) reflections of the $\alpha-\mathrm{TiO}_{2}$ phase become broader as more $\mathrm{Li}$ is inserted. Meanwhile, as shown in Fig. $8 \mathrm{~A}(\mathrm{ii})$, the (011) reflection of the $\beta-\mathrm{Li}_{0.5} \mathrm{TiO}_{2}$ phase decreases in FWHM, the (204) reflection remaining almost constant in FWHM and the (220) reflection showing an increase in FWHM for insertion of more than 0.25 overall $\mathrm{Li}$ composition. Since $\beta$ $\mathrm{Li}_{0.5} \mathrm{TiO}_{2}$ is the newly formed phase, its domain size will only increase (in the case of the two-phase reaction with phase separation inside individual particles) or remain constant (in the case of the particle by particle reaction) as lithiation proceeds, resulting in the narrowing or the invariance of the 

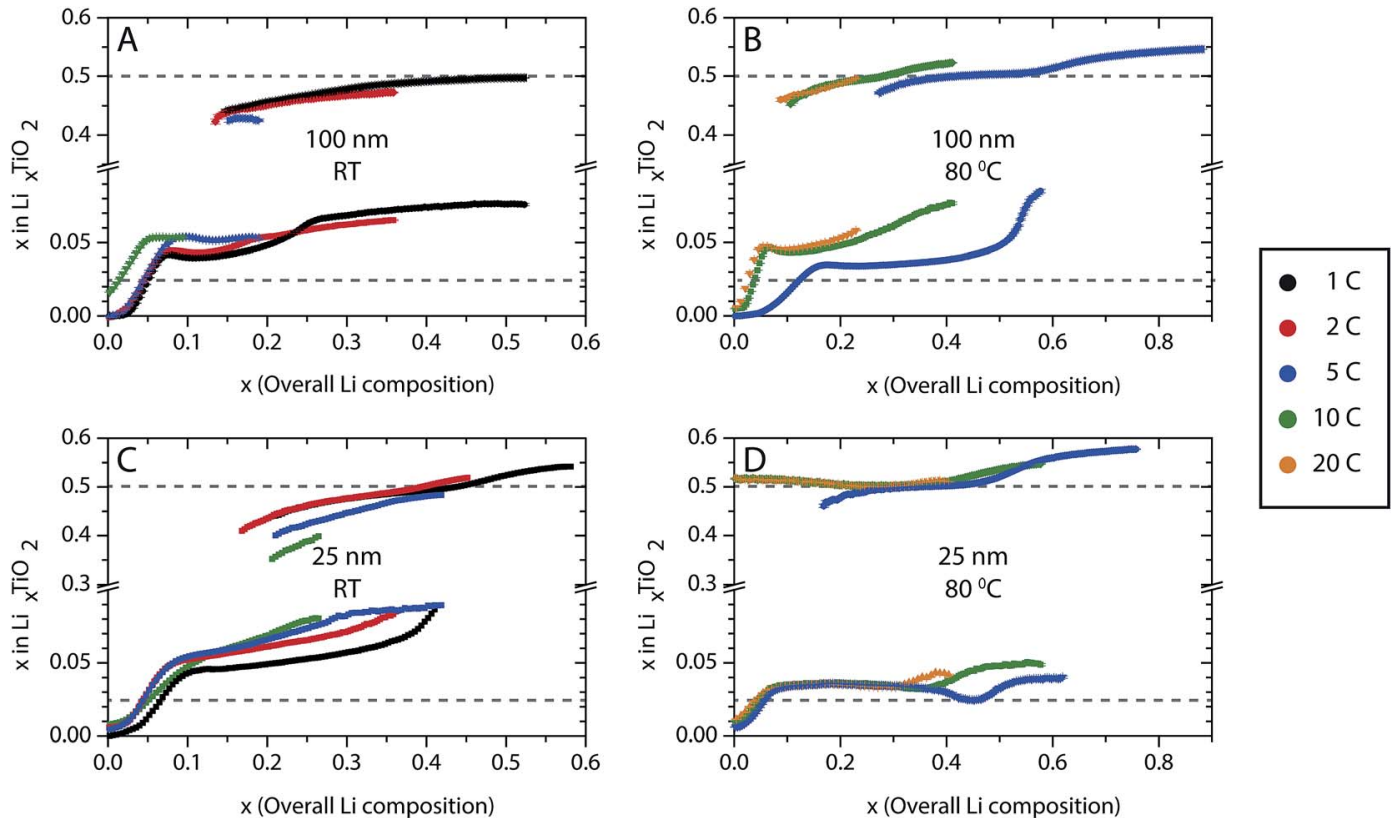

Fig. 7 Evolution of the $\mathrm{Li}$ composition in $\alpha-\mathrm{TiO}_{2}$ and $\beta-\mathrm{Li}_{0.5} \mathrm{TiO}_{2}$ for (A and $\left.\mathrm{B}\right) 100 \mathrm{~nm}$ and (C and D) $25 \mathrm{~nm}$ particles during discharge. Room temperature (RT) results are shown in $A$ and $B$, and elevated temperature experiments are shown in $B$ and $D$. The dashed grey lines indicate the positions for Li solubilities of 0.025 and 0.5 , which are considered as the boundaries of the thermodynamic Li solubility. ${ }^{4}$ The error bars are smaller than the symbols.

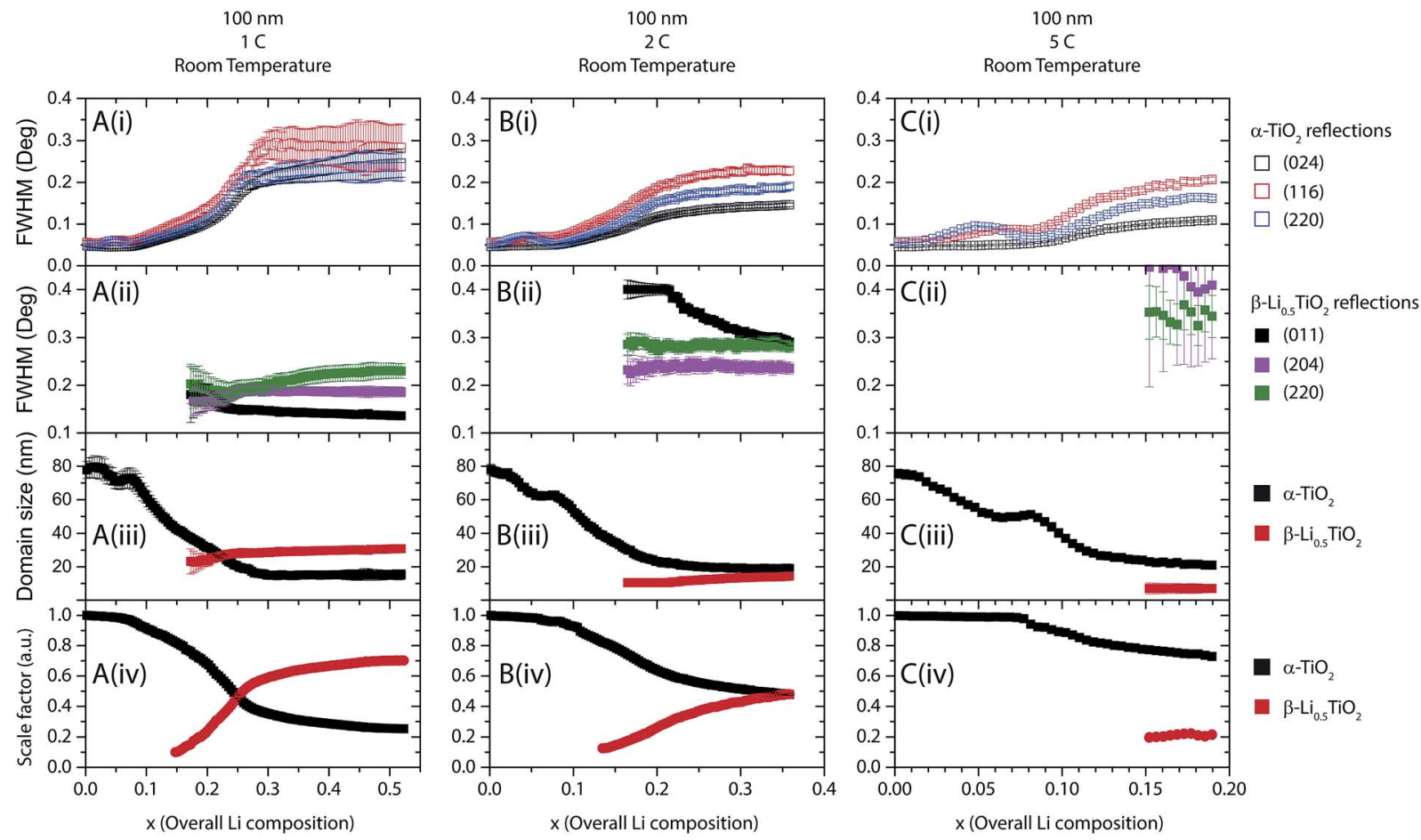

Fig. 8 The evolution of the $\mathrm{FWHM}$ of select reflections from both $\alpha-\mathrm{TiO}_{2}$ and $\beta-\mathrm{Li}_{0.5} \mathrm{TiO}_{2}$ (i and $\mathrm{ii}$ ), the domain size determined from the $\mathrm{FWHM}$ of the (116) reflection for $\alpha-\mathrm{TiO}_{2}$ and the (011) reflection for $\beta-\mathrm{Li}_{0.5} \mathrm{TiO}_{2}$ (iii), and scale factor (iv) as a function of the overall inserted $\mathrm{Li}$ for $100 \mathrm{~nm}$ particles during discharge at cycle rates of (A) $1 C,(B) 2 C$ and (C) $5 C$ at room temperature.

peak width, respectively. The non-monotonic change in the FWHM of the $\beta-\mathrm{Li}_{0.5} \mathrm{TiO}_{2}$ (220) reflection suggests that the dominant peak broadening mechanism is microstrain rather than domain size broadening. In fact, the FWHM observed at the beginning of lithiation for all the select $\alpha-\mathrm{TiO}_{2}$ reflections is only $0.05^{\circ}(2 \theta)$, yet the FWHM of the select $\beta-\mathrm{Li}_{0.5} \mathrm{TiO}_{2}$ reflections, with the exception of the (011) reflection during $5 \mathrm{C}$ discharge at $80^{\circ} \mathrm{C}$ (Fig. 9A), are all larger than $0.1^{\circ}(2 \theta)$. Hence, 

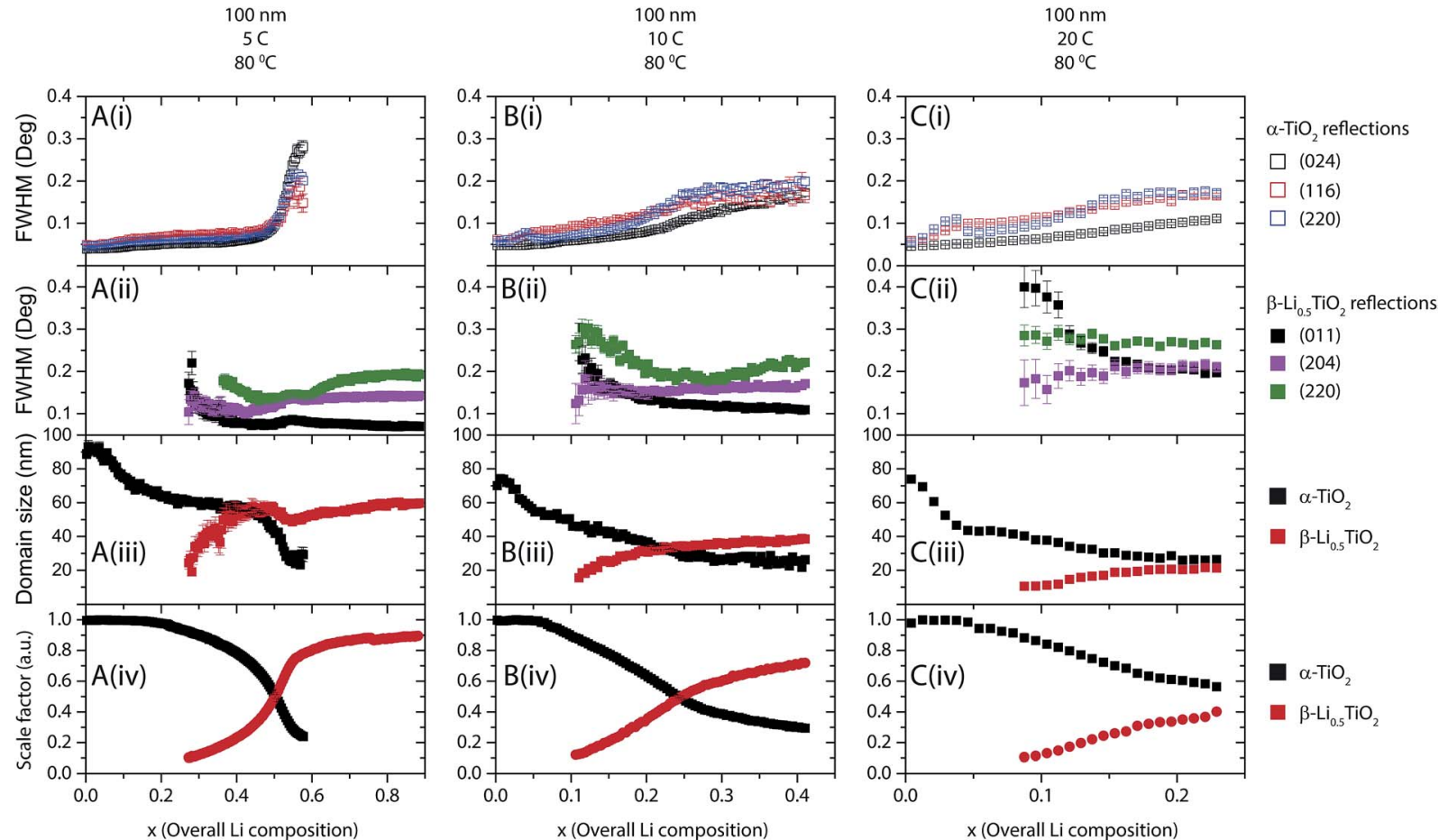

Fig. 9 The evolution of the FWHM of select reflections from both $\alpha-\mathrm{TiO}_{2}$ and $\beta-\mathrm{Li}_{0.5} \mathrm{TiO}_{2}$ (i and $\mathrm{ii}$ ), the domain size determined from $\mathrm{FWHM}$ of the (116) reflection for $\alpha-\mathrm{TiO}_{2}$ and the (011) reflection for $\beta-\mathrm{Li}_{0.5} \mathrm{TiO}_{2}$ (iii), and scale factor (iv) as a function of the overall inserted $\mathrm{Li}$ for $100 \mathrm{~nm}$ particles during discharge at cycle rates of (A) $5 \mathrm{C}$, (B) $10 \mathrm{C}$ and (C) $20 \mathrm{C}$ at $80^{\circ} \mathrm{C}$.

the $\beta-\mathrm{Li}_{0.5} \mathrm{TiO}_{2}$ reflections are substantially broadened by microstrain. Previous studies find an increase in the length of the zig-zag Ti-O-Ti chain along the $b$ axis when $\mathrm{Li}$ is intercalated. ${ }^{5}$ This leads to $7 \%$ increase and $4 \%$ decrease in the $b$ and $c$ lattice parameters, respectively, but only a $0.5 \%$ increase in the a lattice parameter when $\alpha-\mathrm{TiO}_{2}$ is transformed to $\beta-\mathrm{Li}_{0.5} \mathrm{TiO}_{2}$. Hence, the inter-planar spacings for lattice planes that are not parallel to the $b-c$ plane are susceptible to large variations when the Li composition is not homogeneous, that lack of homogeneity being likely caused by slow $\mathrm{Li}$ diffusion in $\beta-\mathrm{Li}_{0.5} \mathrm{TiO}_{2}{ }^{{ }^{7}}$

If the broadening of all the select reflections is assumed to be due largely to the finite domain size effect, the domain size of each phase can be deduced using the Scherrer formula. Fig. $8 \mathrm{~A}$ (iii) shows the evolution of the domain size deduced from FWHM of the (116) reflection of $\alpha-\mathrm{TiO}_{2}$ and the (011) reflection of $\beta-\mathrm{Li}_{0.5} \mathrm{TiO}_{2}$. It is seen that the domain size of $\alpha-\mathrm{TiO}_{2}$ decreases from $80 \mathrm{~nm}$ to $73 \mathrm{~nm}$ from an overall $\mathrm{Li}$ composition of 0 to 0.07 . This slight initial apparent decrease of $7 \mathrm{~nm}$ in the domain size of $\alpha-\mathrm{TiO}_{2}$ is again attributed to the microstrain induced by $\mathrm{Li}$ composition variation within the limited solid solution of $\alpha-\mathrm{TiO}_{2}$, because $\alpha-\mathrm{TiO}_{2}$ is the only phase present when the overall Li composition is between 0 and 0.07 , i.e. there can be no size-induced broadening. Further Li insertion results in a drastic decrease in the domain size of $\alpha-\mathrm{TiO}_{2}$ from $73 \mathrm{~nm}$ to $16 \mathrm{~nm}$ towards the end of lithiation, while the domain size of $\beta$ $\mathrm{Li}_{0.5} \mathrm{TiO}_{2}$ grows to $30 \mathrm{~nm}$. The growth of the $\beta-\mathrm{Li}_{0.5} \mathrm{TiO}_{2}$ domain at the expense of the $\alpha-\mathrm{TiO}_{2}$ one is expected for a two-phase reaction with the nucleation and growth of a second phase within the particles of the first phase. The fact that this process is captured by powder XRD, which measures a large number of crystallites at a time, indicates the two-phase reaction occurs simultaneously in all particles. Although the domain size of $\beta$ $\mathrm{Li}_{0.5} \mathrm{TiO}_{2}$ at the end of lithiation appears to be small, even though it constitutes $70 \%$ of the total phase fraction (Fig. $8 \mathrm{~A}(\mathrm{iv}))$, the small domain size $(30 \mathrm{~nm})$ of $\beta-\mathrm{Li}_{0.5} \mathrm{TiO}_{2}$ could be the result of more than one $\alpha-\mathrm{TiO}_{2} / \beta-\mathrm{Li}_{0.5} \mathrm{TiO}_{2}$ interface per particle $^{20}$ and/or a concurrent microstrain broadening due to the $\mathrm{Li}$ composition variation of $\beta-\mathrm{Li}_{0.5} \mathrm{TiO}_{2}$.

As shown in Fig. 8B and C, increasing the cycling rate to $2 \mathrm{C}$ and $5 \mathrm{C}$ does not qualitatively change the behaviour of FWHM of the reflections: the $\alpha-\mathrm{TiO}_{2}$ reflections increase while the $\beta$ $\mathrm{Li}_{0.5} \mathrm{TiO}_{2}$ reflections decrease or remain constant in FWHM with increasing overall $\mathrm{Li}$ composition, indicating the same twophase reaction with the $1 \mathrm{C}$ discharge. It is noted that FWHM of the $\beta-\mathrm{Li}_{0.5} \mathrm{TiO}_{2}$ reflections increases with the cycling rate: for example, as shown in Fig. 8A-C(ii), the FWHM of the (204) reflection of $\beta-\mathrm{Li}_{0.5} \mathrm{TiO}_{2}$ is $0.19^{\circ}, 0.36^{\circ}$, and $0.4^{\circ}(2 \theta)$ for $1 \mathrm{C}, 2 \mathrm{C}$, and $5 \mathrm{C}$, respectively, suggesting the formation of smaller $\beta$ $\mathrm{Li}_{0.5} \mathrm{TiO}_{2}$ domains or larger microstrain with increasing rate. Broad reflections with weak intensities can lead to large uncertainties in the determination of FWHM, as can be seen in the fitting pattern for the $\beta-\mathrm{Li}_{0.5} \mathrm{TiO}_{2}$ (011) reflection (whose FWHM is not presented in Fig. 8C for this reason) in Fig. $\mathrm{S}^{\mathrm{C}} \dagger$ for the overall $\mathrm{Li}$ composition of 0.19 during $5 \mathrm{C}$ discharge at room temperature. As with discharge at room temperature, cycles at $80^{\circ} \mathrm{C}$ for $100 \mathrm{~nm}$ particles (Fig. 9) still proceed by a twophase reaction, the $\alpha-\mathrm{TiO}_{2}$ domain size decreasing and the $\beta$ $\mathrm{Li}_{0.5} \mathrm{TiO}_{2}$ domain size increasing with increasing overall $\mathrm{Li}$ 
composition. Our observation is consistent with the previous room temperature in situ XRD study, ${ }^{9}$ which reported a twophase mechanism for the phase transition of $130 \mathrm{~nm}$ anatase $\mathrm{TiO}_{2}$ particles at a discharge rate of $\mathrm{C} / 120$. The simultaneous nucleation in all particles, as opposed to particle by particle nucleation, is attributed to the much higher rate applied in this study.

The lithiation process of $100 \mathrm{~nm} \mathrm{TiO}_{2}$ particles is summarised in Fig. 10: (i) lithiation starts with a single phase reaction in the $\alpha-\mathrm{TiO}_{2}$ phase, followed by (ii) simultaneous nucleation of $\beta$ $\mathrm{Li}_{0.5} \mathrm{TiO}_{2}$ domains in all particles; (iii) the $\beta-\mathrm{Li}_{0.5} \mathrm{TiO}_{2}$ domains continue to grow until all the $\alpha-\mathrm{TiO}_{2}$ domains are transformed into $\beta-\mathrm{Li}_{0.5} \mathrm{TiO}_{2}$.

\section{$25 \mathrm{~nm} \mathrm{TiO}_{2}$ particles}

The fitting results for $25 \mathrm{~nm}$ particles are shown in Fig. 11 and 12 for cycles at room temperature and $80{ }^{\circ} \mathrm{C}$, respectively. Typical peak fitting results can be found in Fig. S6. $\dagger$ During room temperature 1C discharge (Fig. 11A(i)) the FWHM of the $\alpha$ $\mathrm{TiO}_{2}$ reflections increases from $0.2^{\circ}$ to $0.3^{\circ}(2 \theta)$ from an overall $\mathrm{Li}$ composition of 0 to 0.4 . The evolution of the $\beta-\mathrm{Li}_{0.5} \mathrm{TiO}_{2}$ reflections, shown in Fig. $11 \mathrm{~A}(\mathrm{ii})$, follows the same trend as observed for the $100 \mathrm{~nm}$ particles: the FWHM of the (011) and (204) reflections decreases with increasing overall Li composition, while the FWHM of the (220) reflection decreases first until the overall Li composition reaches 0.45 , after which it increases again. Fig. 11A(iii) shows the domain size as a function of overall Li composition deduced from the FWHM of the (116) reflection of $\alpha-\mathrm{TiO}_{2}$ and the (011) reflection of $\beta-\mathrm{Li}_{0.5} \mathrm{TiO}_{2}$. As shown in Fig. 11A(iii) for a 1C discharge, the domain size of $\alpha$ $\mathrm{TiO}_{2}$ decreases from 23 to $15 \mathrm{~nm}$ when the overall Li composition increases from 0 to 0.4 , meanwhile the phase fraction of $\alpha$ $\mathrm{TiO}_{2}$ decreases by $80 \%$. If the two phases in a spherical particle assume a core-shell morphology, where the core is $\alpha-\mathrm{TiO}_{2}$ and the shell is $\beta-\mathrm{Li}_{0.5} \mathrm{TiO}_{2}$, the volume fraction of a $15 \mathrm{~nm}$ diameter spherical core of $\alpha-\mathrm{TiO}_{2}$ in a $23 \mathrm{~nm}$ diameter spherical particle would correspond to $28 \%$, which is very close to the $20 \%$ phase fraction of the $\alpha-\mathrm{TiO}_{2}$ phase. However, this core-shell arrangement would leave a shell $\left(\beta-\mathrm{Li}_{0.5} \mathrm{TiO}_{2}\right)$ of $4 \mathrm{~nm}$ thick, which is far less than the value, $17 \mathrm{~nm}$, determined from the Scherrer formula. Therefore, the only plausible explanation is that the lithiation takes place particle by particle and the decrease in the domain size of $\alpha-\mathrm{TiO}_{2}$ from $23 \mathrm{~nm}$ to $15 \mathrm{~nm}$ is associated with the microstrain developed in $\alpha-\mathrm{TiO}_{2}$. This microstrain could result from the distortion present in the $\alpha$ $\mathrm{TiO}_{2}$ phase and/or the Li composition variation between different $\alpha-\mathrm{TiO}_{2}$ particles. The particle-by-particle mechanism also stipulates a constant domain size for $\beta-\mathrm{Li}_{0.5} \mathrm{TiO}_{2}$, hence, the very large broadening at the point where the $\beta-\mathrm{Li}_{0.5} \mathrm{TiO}_{2}$ peaks emerge is also associated with the microstrain effect, which is likely to be caused by compositional variation between $\beta$ $\mathrm{Li}_{0.5} \mathrm{TiO}_{2}$ particles. Reactions at higher rates, shown in Fig. 11B for 2C and Fig. 11C for 5C, exhibit qualitatively similar behaviour and also proceed particle by particle. The domain size of $\beta$ $\mathrm{Li}_{0.5} \mathrm{TiO}_{2}$ at $5 \mathrm{C}$ discharge (Fig. $11 \mathrm{C}$ ) is $12 \mathrm{~nm}$ at the overall $\mathrm{Li}$ composition of 0.4 , well below $20 \mathrm{~nm}$ observed at the end charge for cycle rates of $1 \mathrm{C}$ and $2 \mathrm{C}$, despite the dominant presence of the $\beta-\mathrm{Li}_{0.5} \mathrm{TiO}_{2}$ phase. Hence, this provides a direct evidence for the presence of microstrain in $\beta-\mathrm{Li}_{0.5} \mathrm{TiO}_{2}$.

When the temperature is raised to $80^{\circ} \mathrm{C}$, for example, for the cycle rate of 5C as shown in Fig. 12A(i), the FWHM of the (024) reflection of $\alpha-\mathrm{TiO}_{2}$ remains almost constant at $\sim 0.18^{\circ}$ throughout the entire overall Li composition, while the FWHM of the (116) and (220) reflections of $\alpha-\mathrm{TiO}_{2}$, after a rapid initial increase from 0 to 0.07 overall $\mathrm{Li}$, which is attributed to the microstrain effect, also shows very little change over the rest of the overall Li composition range. As shown in Fig. 12A(ii), the FWHM of the (011) reflection of $\beta-\mathrm{Li}_{0.5} \mathrm{TiO}_{2}$ decreases monotonically with increasing overall $\mathrm{Li}$ composition, whereas the FWHM of the (204) and (220) reflections decreases from 0.2 to 0.45 overall $\mathrm{Li}$ composition and increases from 0.45 overall $\mathrm{Li}$ composition onwards. The increase in the FWHM of the (204) and (220) reflections of $\beta-\mathrm{Li}_{0.5} \mathrm{TiO}_{2}$ is attributed to the microstrain effect. As shown in Fig. 12A(iii), the domain size of $\alpha-\mathrm{TiO}_{2}$ determined from FWHM of the (116) reflection of $\alpha-\mathrm{TiO}_{2}$ remains effectively invariant at $\sim 20 \mathrm{~nm}$ except the small initial drop from $23 \mathrm{~nm}$ to $20 \mathrm{~nm}$ from 0 to 0.07 overall Li composition.

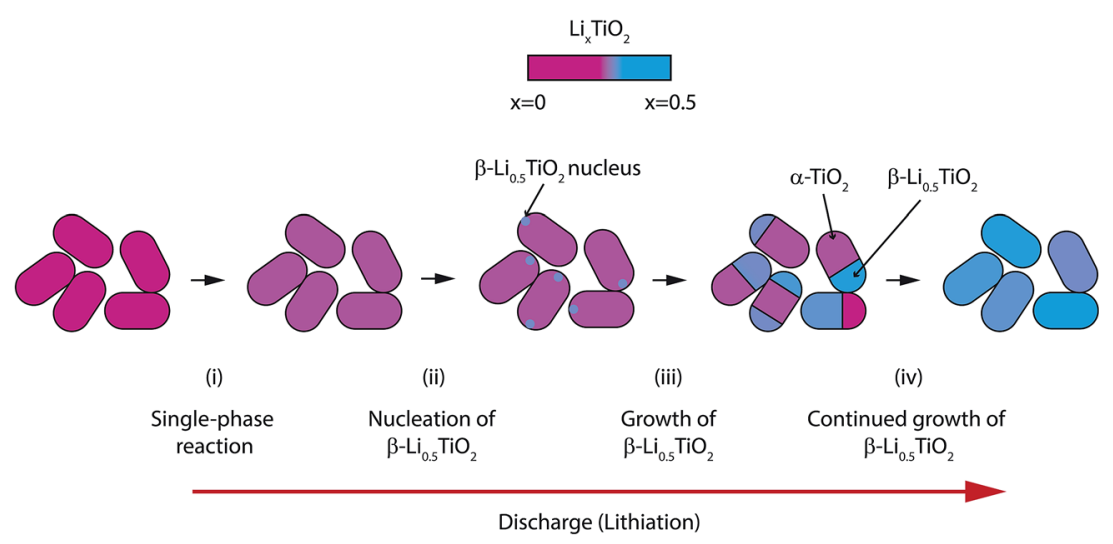

Fig. 10 Schematic illustration of the phase transition occurring in $100 \mathrm{~nm}$ anatase $\mathrm{TiO}_{2}$ particles during high rate discharge. The lithiation proceeds firstly by a solid solution reaction in the $\alpha-\mathrm{TiO}_{2}$ phase (i) followed by the nucleation of $\beta-\mathrm{Li}_{0.5} \mathrm{TiO}_{2}$ (ii). The $\beta-\mathrm{Li}_{0.5} \mathrm{TiO}_{2}$ domains grow in size until the entire particle comprises a single phase (iii and iv). 

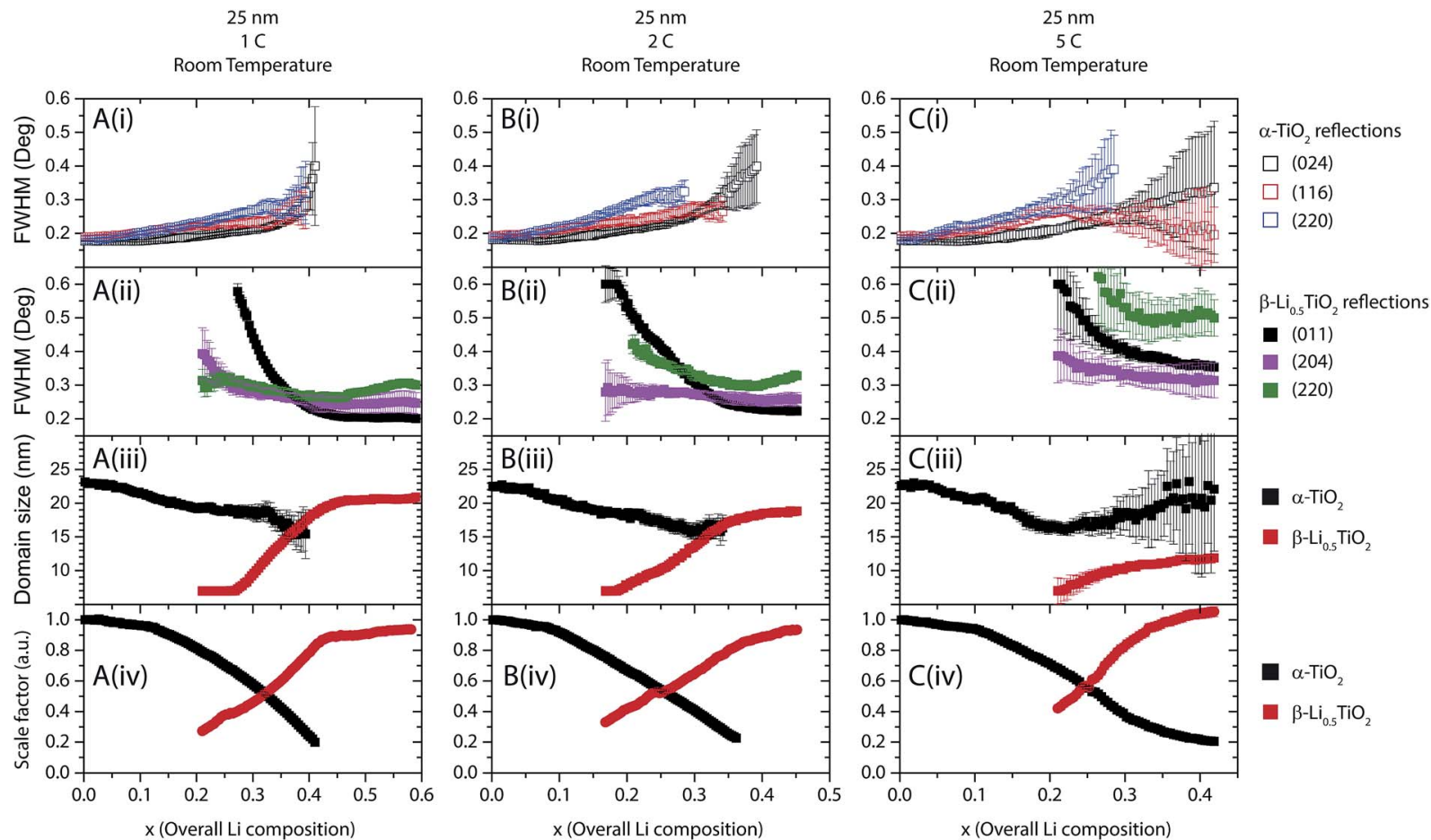

Fig. 11 The evolution of the FWHM of select reflections from both $\alpha-\mathrm{TiO}_{2}$ and $\beta-\mathrm{Li}_{0.5} \mathrm{TiO}_{2}$ (i and ii), the domain size determined from the $\mathrm{FWHM}$ of the (116) reflection for $\alpha-\mathrm{TiO}_{2}$ and the (011) reflection for $\beta-\mathrm{Li}_{0.5} \mathrm{TiO}_{2}$ (iii), and scale factor (iv) as a function of the overall inserted $\mathrm{Li}$ for $25 \mathrm{~nm}$ particles during discharge at cycle rates of (A) $1 \mathrm{C},(\mathrm{B}) 2 \mathrm{C}$ and (C) $5 \mathrm{C}$ discharge at room temperature.
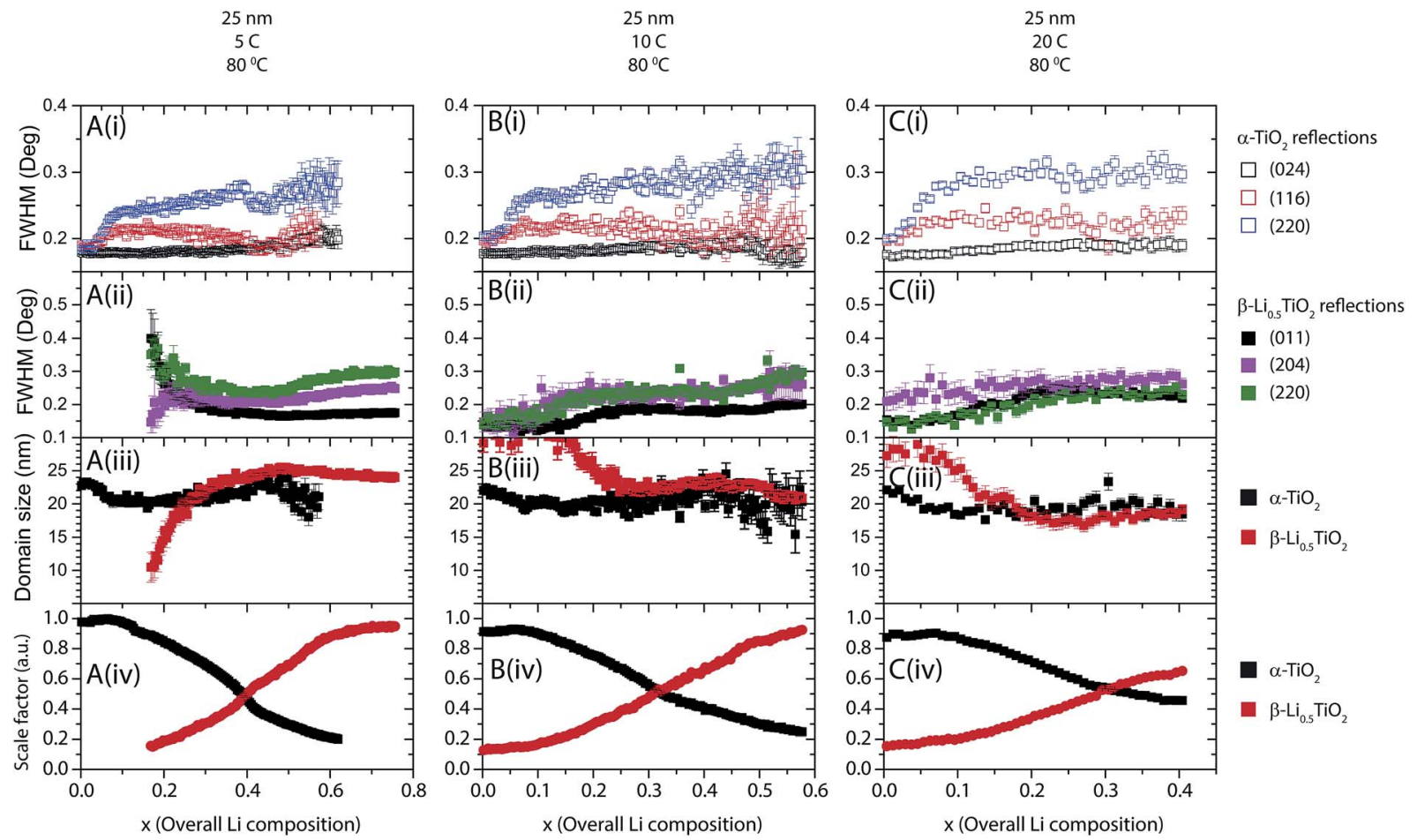

Fig. 12 The evolution of the FWHM of select reflections from both $\alpha-\mathrm{TiO}_{2}$ and $\beta-\mathrm{Li}_{0.5} \mathrm{TiO}_{2}$ ( $\mathrm{i}$ and ii), the domain size determined from the FWHM of the (116) reflection for $\alpha-\mathrm{TiO}_{2}$ and the (011) reflection for $\beta-\mathrm{Li}_{0.5} \mathrm{TiO}_{2}$ (iii), and scale factor (iv) as a function of the overall inserted $\mathrm{Li}$ for $25 \mathrm{~nm}$ particles during discharge at cycle rates of (A) $5 \mathrm{C}$, (B) $10 \mathrm{C}$ and (C) $20 \mathrm{C}$ discharge at $80^{\circ} \mathrm{C}$. 
Since the 10C and 20C discharge was carried out consecutively on the same cell after the cycle at $5 \mathrm{C}$, a small amount $(\sim 10 \%)$ of the $\beta-\mathrm{Li}_{0.5} \mathrm{TiO}_{2}$ phase (residual $\beta-\mathrm{Li}_{0.5} \mathrm{TiO}_{2}$ ), which did not transform back to $\alpha-\mathrm{TiO}_{2}$, was present at the beginning of $10 \mathrm{C}$ and also 20C discharge (shown in Fig. S6C $†$ for 10C charge). The presence of the residual $\beta-\mathrm{Li}_{0.5} \mathrm{TiO}_{2}$ phase complicates the interpretation of the FWHM of the $\beta-\mathrm{Li}_{0.5} \mathrm{TiO}_{2}$ reflections: the increase, as opposed to the decrease as observed at all other rates, in the FWHM of the $\beta-\mathrm{Li}_{0.5} \mathrm{TiO}_{2}$ reflections, as shown in Fig. $12 \mathrm{~B}(\mathrm{ii})$ and $\mathrm{C}(\mathrm{ii})$ for $10 \mathrm{C}$ and $20 \mathrm{C}$, respectively, is attributed to the formation of $\beta-\mathrm{Li}_{0.5} \mathrm{TiO}_{2}$ particles that are not compositionally homogeneous. Nonetheless, interpretation of the FWHM of the $\alpha-\mathrm{TiO}_{2}$ reflections and the deduced domain size of $\alpha-\mathrm{TiO}_{2}$, is not affected: the effectively invariant domain size $(\sim 20 \mathrm{~nm})$ of $\alpha-\mathrm{TiO}_{2}$ throughout the entire overall $\mathrm{Li}$ composition for the 10C and 20C discharge, shown in Fig. 12B(iii) and $\mathrm{C}(\mathrm{iii})$, respectively, is consistent with the particle-by-particle reaction mechanism.

The particle-by-particle reaction mechanism is in agreement with the previous findings from in $s i t u^{9}$ and $e x s i t u^{4}$ XRD studies of anatase $\mathrm{TiO}_{2}$ nanoparticles ( $15 \mathrm{~nm}$ and $<40 \mathrm{~nm}$, respectively), and is attributed to the relatively high energy of the $\alpha-\mathrm{TiO}_{2} / \beta$ $\mathrm{Li}_{0.5} \mathrm{TiO}_{2}$ interface, whose disappearance reduces the total energy of the system. Fig. 13 summarises the lithiation process: (i) the initial lithiation involves a single phase reaction in the $\alpha$ $\mathrm{TiO}_{2}$ phase; (ii) further lithiation triggers the transformation of an entire $\alpha-\mathrm{TiO}_{2}$ domain into a $\beta-\mathrm{Li}_{0.5} \mathrm{TiO}_{2}$ one (stages (ii-iv)). This transformation does not occur simultaneously in all particles but proceeds from particle to particle until every particle is transformed.

Discussion on the nature of the "instantaneous" $\alpha-\mathrm{TiO}_{2}$ to $\beta$ $\mathrm{Li}_{0.5} \mathrm{TiO}_{2}$ phase transition of $25 \mathrm{~nm} \mathrm{TiO}_{2}$ particles

What remains unanswered from the preceding sections is the microscopic process by which an entire $\alpha-\mathrm{TiO}_{2}$ domain transforms into a $\beta-\mathrm{Li}_{0.5} \mathrm{TiO}_{2}$ one. Analogous to the case for $\mathrm{LiFePO}_{4}$ nanoparticles, two mechanisms need to be examined: (i) phase transition by a continuous structural change from $\alpha-\mathrm{TiO}_{2}$ to $\beta$ $\mathrm{Li}_{0.5} \mathrm{TiO}_{2}$, and (ii) nucleation of $\beta-\mathrm{Li}_{0.5} \mathrm{TiO}_{2}$ in $\alpha-\mathrm{TiO}_{2}$ domain followed immediately (i.e., essentially instantaneous) by the fast propagation of the phase boundary (the domino-cascade mechanism $^{\mathbf{1 0}}$ ).

Since the transformation from $\alpha-\mathrm{TiO}_{2}$ to $\beta-\mathrm{Li}_{0.5} \mathrm{TiO}_{2}$ involves a change in crystal symmetry from $I 4_{1} /$ amd to Imma, corresponding to a group-subgroup relationship, a continuous path, if there is one, between the two phases must undergo a secondorder phase transition. Although a continuous structural transition between $\alpha-\mathrm{TiO}_{2}$ and $\beta-\mathrm{Li}_{0.5} \mathrm{TiO}_{2}$ is found, with the use of the programme ISOTROPY, ${ }^{21}$ to be allowed by Landau theory, ${ }^{22}$ whether it will occur depends on the energetics and kinetics of various transition pathways.

The Gibbs free energy diagram for different phase transition paths is displayed in Fig. 14. If the transformation from $\alpha-\mathrm{TiO}_{2}$ to $\beta-\mathrm{Li}_{0.5} \mathrm{TiO}_{2}$ proceeds by a continuous overpotential driven structural phase transition, the energy will evolve along the solid black curve during lithiation: the initial lithiation involves the single-phase reaction of $\alpha-\mathrm{TiO}_{2}$ until it reaches the critical point $\mathrm{O}$, beyond which the energy for the high symmetry phase $\left(\alpha-\mathrm{TiO}_{2}\right)$ becomes higher than the low symmetry one ( $\beta$ $\left.\mathrm{Li}_{0.5} \mathrm{TiO}_{2}\right)$. Therefore, traversing across point $\mathrm{O}$ from left to right along the solid black line, the entire nanoparticle will first transform to a lower symmetry (orthorhombic) phase, and then continue to be lithiated via a single-phase reaction. This transition across point $\mathrm{O}$ should manifest itself in the XRD measurement as the branching of a single $(0 \mathrm{kl})(\mathrm{l}$ can be 0$)$ reflection into two separate, $(0 k l)$ and $(h 0 l)$, reflections, which is characteristic of a continuous structural (second-order) transition. In the case studied here, no branching of the (024) reflection of $\alpha-\mathrm{TiO}_{2}$ into the (024) and (204) reflections of $\beta$ $\mathrm{Li}_{0.5} \mathrm{TiO}_{2}$ is observed. In addition, cycling at $10 \mathrm{C}$ and $20 \mathrm{C}$ should have induced an appreciable fraction of the $\mathrm{TiO}_{2}$ particles to react at a time, as observed for $\mathrm{LiFePO}_{4},{ }^{1,2}$ if a continuous structural transition did take place.

If the transformation takes place via a nucleation and growth mechanism, which is found to be the case in this work, the $\mathrm{Li}$

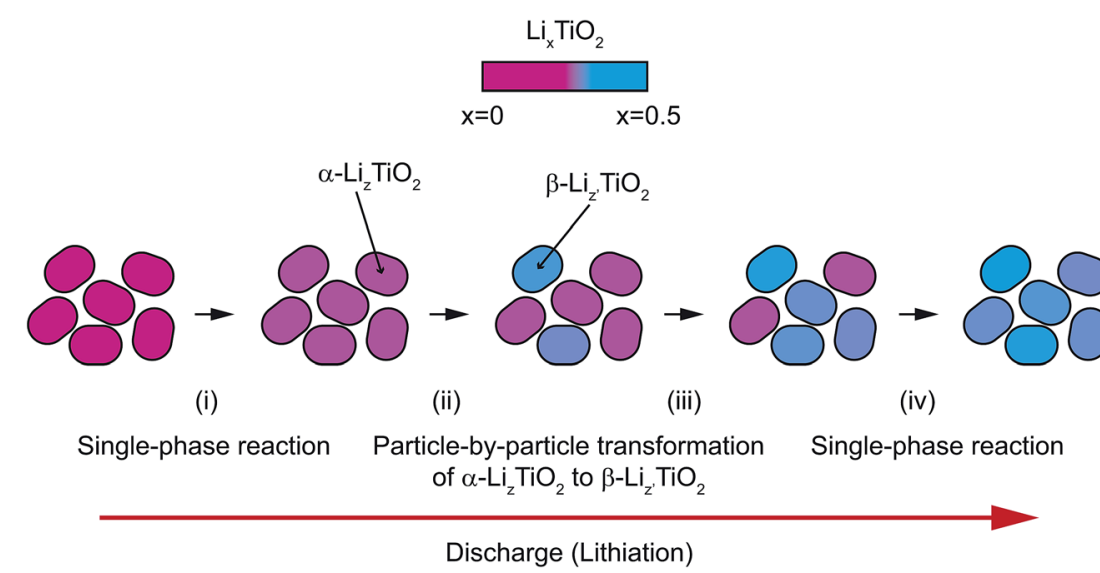

Fig. 13 Schematic illustration of the phase transition occurring in $25 \mathrm{~nm}$ anatase $\mathrm{TiO}_{2}$ particles during high rate discharge. Lithiation proceeds firstly by a solid solution reaction in the $\alpha-\mathrm{TiO}_{2}$ phase (i) followed by the sequential (particle-by-particle) transformation from $\alpha-\mathrm{Li}_{z} \mathrm{TiO} \mathrm{O}_{2}$ to $\beta$ $\mathrm{Li}_{z^{\prime}} \mathrm{TiO}_{2}$ particles (ii-iv), where $z>0.025$ and $z^{\prime}<0.5$. 


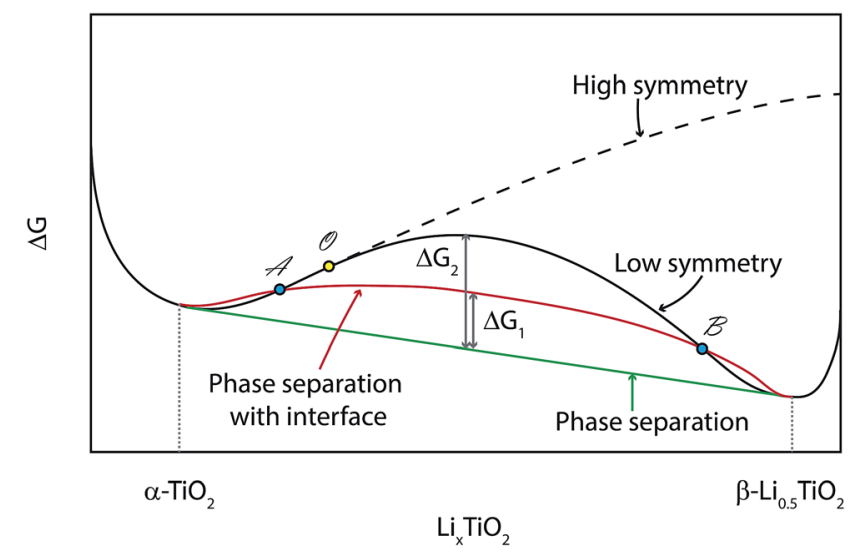

Fig. 14 Illustration of the change in Gibbs free energy for various phase transition paths. The solid black line represents a continuous structural transition (second-order phase transition), and the critical point is marked by $\bigcirc$ (solid yellow circle). The dashed black line is the projected energy curve if there is no reduction to lower symmetry. The solid green line is the common tangent construction that determines the lowest possible energy of a system with a mixture of $\alpha-\mathrm{TiO}_{2}$ and $\beta$ $\mathrm{Li}_{0.5} \mathrm{TiO}_{2}$ not coexisting in the same particle. The solid red line is the modified energy of a system with a mixture of $\alpha-\mathrm{TiO}_{2}$ and $\beta-\mathrm{Li}_{0.5} \mathrm{TiO}_{2}$ separated by a phase boundary.

composition in the nanoparticle will evolve along the solid red curve, which differs from the equilibrium energy (solid green) only by an $\alpha-\mathrm{TiO}_{2} / \beta-\mathrm{Li}_{0.5} \mathrm{TiO}_{2}$ interfacial energy, $\Delta G_{1}$. Phase separation will be induced within the composition between $\mathrm{A}$ and $\mathrm{B}$, i.e. between the points where the red curve crosses the black curve. Consequently, the lithiation process is limited by the rate of nucleation.

Kinetics aside, the transformation should take the route that lies lower in energy, and it is possible that the energy barrier for the second-order phase transition (solid black curve) is too high for it to occur. In addition, the interfacial energy, $\Delta G_{1}$, can be minimised by forming an interface along a zero-strain plane, ${ }^{7}$ hence favouring the two-phase mechanism with a fast propagation of the interface. In this work, when Li diffusion is improved at high temperature, the lithiation process becomes almost independent of the cycling rate and remains distinctively two-phase, i.e. the lattice parameters of each phase remain almost invariant in the regime when both phases are present, as seen in Fig. 6D. This observation suggests any lattice parameter deviation from equilibrium values observed for the room temperature cycling is primarily due to slow Li diffusion, which is found to cause deviations in lattice parameters even during lithiation at a rate of $\mathrm{C} /$ 120. ${ }^{9}$ It must be pointed out that the deviation from equilibrium observed here is fundamentally different from the non-equilibrium phase transition observed for $\mathrm{LiFePO}_{4}$ at high rates: the nonequilibrium phase transition of $\mathrm{LiFePO}_{4}$ is rooted in the small energy difference between the equilibrium and non-equilibrium phase transition path, ${ }^{23}$ which is not available to anatase $\mathrm{TiO}_{2}$.

\section{Conclusions}

The lithiation mechanism of anatase $\mathrm{TiO}_{2}$ particles during $\mathrm{Li}$ insertion was investigated by in situ XRD as a function of rate, particle size and cycling temperature. Li solubilities of the end member phases, $\alpha-\mathrm{TiO}_{2}$ and $\beta-\mathrm{Li}_{0.5} \mathrm{TiO}_{2}$, are found to increase noticeably with increasing rate, yet no continuous transition from $\alpha-\mathrm{TiO}_{2}$ to $\beta-\mathrm{Li}_{0.5} \mathrm{TiO}_{2}$ is observed, even at a cycle rate of $20 \mathrm{C}$, in contrast to the behaviour observed for $\mathrm{LiFePO}_{4} \cdot{ }^{1,2} \mathrm{An}$ increase in temperature from room temperature to $80^{\circ} \mathrm{C}$ results a significant improvement in the electrode's electrochemical performance although the reaction still proceeds by a two-phase reaction. The Li solubility exceeds the thermodynamic limit and increases with cycling rate for both the $\alpha-\mathrm{TiO}_{2}$ and $\beta-\mathrm{Li}_{0.5} \mathrm{TiO}_{2}$ phases, due to the kinetic limitation imposed by the finite $\mathrm{Li}$ diffusivity. Domain size information obtained from the line broadening analysis reveals a change in the phase transition mechanism brought about by a reduction in particle size from $100 \mathrm{~nm}$ to $25 \mathrm{~nm}$ : the $100 \mathrm{~nm}$ particles react simultaneously via a conventional nucleation and growth (two-phase) mechanism, while the $25 \mathrm{~nm}$ particles react sequentially again via a twophase, domino-cascade mechanism. (De)lithiation via a firstorder rather than a second-order phase transition may be inherent in phase-separating compounds with end member phases of different symmetries. The lack of a continuous structural phase transition may hinder the reaction kinetics, and the search for high-rate electrode materials should be focused on compounds exhibiting no phase separation or phase-separating compounds with isostructural end member phases.

\section{Acknowledgements}

This research used resources of the Advanced Photon Source, a U.S. Department of Energy (DOE) Office of Science User Facility operated for the DOE Office of Science by Argonne National Laboratory under Contract No. DE-AC02-06CH11357. This work was supported by funding from European Union FP7265368 via the Eurolion Project and the Cambridge Overseas Trust (materials preparation, XRD), and as part of the NorthEast Center for Chemical Energy Storage (NECCES), an Energy Frontier Research Center funded by the U.S. Department of Energy, Office of Science, Basic Energy Sciences under Awards DE-SC0012583 (data analysis). We thank Dr Tao Liu for help with the SEM, Dr Simon Clarke and Dr Michael Carpenter for their helpful comments and discussions, and Dr Kamila Wiaderek, Dr Olaf Borkiewicz, Dr Karena Chapman and Dr Peter Chupas for their help with the setup for XRD measurement.

\section{Notes and references}

1 H. Liu, F. C. Strobridge, O. J. Borkiewicz, K. M. Wiaderek, K. W. Chapman, P. J. Chupas and C. P. Grey, Science, 2014, 344, 1252817.

2 X. Zhang, M. van Hulzen, D. P. Singh, A. Brownrigg, J. P. Wright, N. H. van Dijk and M. Wagemaker, Nano Lett., 2014, 14, 2279-2285.

3 A. Singer, A. Ulvestad, H. Cho, J. W. Kim, J. Maser, R. Harder, Y. S. Meng and O. G. Shpyrko, Nano Lett., 2014, 14, 52955300 . 
4 M. Wagemaker, W. J. H. Borghols and F. M. Mulder, J. Am. Chem. Soc., 2007, 129, 4323-4327.

5 M. Wagemaker, G. J. Kearley, A. A. Van Well, H. Mutka and F. M. Mulder, J. Am. Chem. Soc., 2003, 125, 840-848.

6 D. Murphy, R. Cava, S. Zahurak and A. Santoro, Solid State Ionics, 1983, 9-10, 413-417.

7 A. A. Belak, Y. Wang and A. Van Der Ven, Chem. Mater., 2012, 24, 2894-2898.

8 W. J. H. Borghols, D. Lützenkirchen-Hecht, U. Haake, E. R. H. van Eck, F. M. Mulder and M. Wagemaker, Phys. Chem. Chem. Phys., 2009, 11, 5742-5748.

9 K. Shen, H. Chen, F. Klaver, F. M. Mulder and M. Wagemaker, Chem. Mater., 2014, 26, 1608-1615.

10 C. Delmas, M. Maccario, L. Croguennec, F. Le Cras and F. Weill, Nat. Mater., 2008, 7, 665-671.

11 O. J. Borkiewicz, B. Shyam, K. M. Wiaderek, C. Kurtz, P. J. Chupas and K. W. Chapman, J. Appl. Crystallogr., 2012, 45, 1261-1269.

12 A. A. Coelho, TOPAS v2.0: General profile and structure analysis software for powder diffraction data, Karlsruhe, 2000. 13 M. Järvinen, J. Appl. Crystallogr., 1993, 26, 525-531.
14 T. Ohzuku, T. Kodama and T. Hirai, J. Power Sources, 1985, 14, 153-166.

15 Y.-G. Guo, Y.-S. Hu and J. Maier, Chem. Commun., 2006, 2783-2785.

16 J. S. Chen, Y. L. Tan, C. M. Li, Y. L. Cheah, D. Luan, S. Madhavi, F. Y. C. Boey, L. A. Archer and X. W. Lou, J. Am. Chem. Soc., 2010, 132, 6124-6130.

17 X. P. Gao, Y. Lan, H. Y. Zhu, J. W. Liu, Y. P. Ge, F. Wu and D. Y. Song, Electrochem. Solid-State Lett., 2005, 8, A26.

18 G. Sudant, E. Baudrin, D. Larcher and J.-M. Tarascon, J. Mater. Chem., 2005, 15, 1263-1269.

19 P. Bai, D. A. Cogswell and M. Z. Bazant, Nano Lett., 2011, 11, 4890-4896.

20 M. Wagemaker, R. van de Krol, A. P. Kentgens, A. A. van Well and F. M. Mulder, J. Am. Chem. Soc., 2001, 123, 11454-11461.

21 H. T. Stokes, D. M. Hatch and B. J. Campbell, ISOTROPY Software Suite, iso.byu.edu.

22 L. D. Landau and E. M. Lifshitz, Statistical Physics, Pergamon Press, Oxford, 3rd edn, 1980.

23 R. Malik, F. Zhou and G. Ceder, Nat. Mater., 2011, 10, 587590. 